\title{
Los que se van y los que se quedan ante la educación. Un estudio comparativo-longitudinal de jóvenes en transición a la adultez en México y Estados Unidos
}

The Leavers and the Stayers. A comparative-Iongitudinal study of educational achievement and transitions to adulthood among youth in Mexico and the United States

Rubén G. Rumbaut

Universidad de California, Irvine

rrumbaut@uci.edu

Enrique Martínez Curiel

Universidad de Guadalajara-CU VALLES

emarcuriel@aol.com

30 ANIVERSARIO DE LA GAZETA DE ANTROPOLOGÍA
NÚMERO COORDINADO POR FRANCISCO CHECA OLMOS Y CELESTE JIMÉNEZ DE MADARIAGA

RESUMEN

Este trabajo examina de forma comparativa y longitudinal los logros educativos que han obtenido dos muestras de jóvenes: los que se quedaron con sus familias en su lugar de origen en México, y los del mismo lugar que emigraron a California o nacieron del otro lado de la frontera en los Estados Unidos. Los pocos estudios longitudinales de las trayectorias de hijos de inmigrantes, como CILS en Estados Unidos e ILSEG en España, comparan grupos de jóvenes en el mismo país. El presente estudio, denominado Estudio Longitudinal de Logros Educativos (ELLE) en México y Estados Unidos, no sólo compara con métodos cualitativos y cuantitativos la situación de jóvenes y de sus padres del mismo origen en dos países durante períodos de crisis entre 2008-2012, sino también compara familias de inmigrantes en California en calidad de indocumentados, documentados y ciudadanos americanos.

\section{ABSTRACT}

This paper presents the results of a comparative longitudinal study of educational achievement between two samples of young people: those who stayed with their families in their home town in Mexico, and those from the same place who emigrated to California or were born to immigrant parents in the United States. The few longitudinal studies of the trajectories from adolescence to adulthood of children of immigrants, such as CILS in the U.S. and ILSEG in Spain, compare groups of youth in the same country. This work, the Longitudinal Study of Educational Achievement (ELLE) in Mexico and the United States, employs qualitative and quantitative methods not only to compare the situation of young people and their parents of the same origin in two countries during periods of crisis between 2008-2012, but also compares the outcomes of undocumented, documented and U.S. citizen youth in immigrant families in California.

\section{PALABRAS CLAVE}

educación I inmigrantes indocumentados I desconexión social I expectativas educativas I familias inmigrantes I transición a la adultez KEYWORDS

education I undocumented immigrants I social disconnection I educational expectations I immigrant families I transition to adulthood

\section{Introducción}

Hasta dónde han llegado educativamente los jóvenes que se quedaron con sus familias en su lugar de origen y los que emigraron y nacieron del otro lado de la frontera entre México y Estados Unidos, es el objetivo del estudio. En este trabajo examinamos de forma comparativa y longitudinal los logros educativos que hasta el momento han obtenido los jóvenes que residen en su lugar de origen, Ameca (Jalisco), una comunidad del occidente de México, y los jóvenes hijos de inmigrantes que viven del otro 
lado, en California. El estudio busca examinar las trayectorias educativas que hasta el momento han alcanzado los hijos que tienen un mismo origen de padres que provienen de una misma comunidad en México.

Los estudios longitudinales de las trayectorias de hijos de inmigrantes son escasos. En los Estados Unidos, el más conocido es CILS (Children of Immigrants Longitudinal Study), realizado a través de diez años en dos costas del país, San Diego, California y Miami, Florida (Portes y Rumbaut 2011, 2005; Rumbaut y Portes 2001). En España, ILSEG (Investigación Longitudinal de la Segunda Generación) ha comparado muestras de hijos de inmigrantes en Madrid y Barcelona con encuestas basadas en CILS (Portes et al. 2011). Ambos, sin embargo, comparan grupos de jóvenes en el mismo país. El presente estudio -denominado Estudio Longitudinal de Logros Educativos (ELLE) en México y Estados Unidos- es novedoso en otros aspectos: no sólo compara la situación de jóvenes y de sus padres del mismo origen en dos países, sino en el caso de las familias que inmigraron a California compara la situación de los indocumentados con los documentados y los que ya son ciudadanos americanos.

Es más, el estudio se sitúa como un experimento natural en un contexto permeado por una grave crisis económica, financiera y de inseguridad que azota en ambos países. Para el caso de Estados Unidos no sólo se debe a la difícil situación socioeconómica de las familias, sino también al hecho de un ambiente hostil en contra de los indocumentados y de su persecución por el estado, aumentando las deportaciones a cifras históricas; y por el lado de México, las condiciones de inseguridad y violencia son inimaginables, dado los niveles de tragedia y zozobra producto de la guerra contra el narcotráfico y de la incertidumbre que se vive en gran parte del territorio mexicano, donde las familias y sus hijos se ven envueltos en una serie de adversidades que impactan en el rumbo de sus vidas, tanto al interior de la familia como de forma individual. Bajo estas circunstancias los jóvenes tendrán que transitar hacia la adultez.

El presente trabajo forma parte de un estudio más amplio sobre jóvenes y adolescentes en México y Estados Unidos, donde se analizan múltiples variables que impactan los logros educativos y ocupacionales en su tránsito a la adultez. Las fuentes y el método que se han utilizado para el desarrollo de este trabajo responden al carácter singular del estudio, analizando el contexto de origen y destino como un proceso y como un todo, que permita tener una comprensión más amplia de la transición de los jóvenes a la adultez. Para el análisis de esta investigación se incorporan datos cualitativos y cuantitativos recogidos durante el ciclo escolar 2008-2009, y una segunda encuesta de seguimiento, justo tres años después, durante abril, agosto y septiembre de 2012 en ambos lados entre Estados Unidos y México: California versus Ameca.

\section{Por qué una mirada comparativa y longitudinal de jóvenes en Ameca y California}

El primer trabajo que estudió a los migrantes desde el origen y destino fue realizado por William I. Thomas y Florian Znaniecki, y publicado en 1918-1920 como The Polish Peasant in Europe and America. Casi un siglo después hemos realizado un estudio de investigación similar por sus características metodológicas, por tratarse de abordar a los migrantes y sus familias desde ambos lados, en esta ocasión desde México y Estados Unidos. Llevar a cabo este tipo de trabajo es un reto mayor en el diseño y la metodología porque el proceso se vuelve más complejo cuando entran en juego más aristas en la interpretación y análisis; por ello, la característica principal de la investigación es mostrar ambas miradas de los actores, con un carácter binacional, donde examinamos a los migrantes y sus familias como sujetos inmersos en contextos sumamente diferentes y complejos situados en ambos países.

Sin embargo, en este trabajo intentamos ir más allá que el trabajo de Thomas y Znaniecki, dado que "la vida de un número creciente de personas ya no puede ser entendida contemplando sólo lo que acontece dentro de los límites nacionales" (Levitt y Glick-Schiller 2004: 1003); existe la necesidad de contar con estudios comparativos de carácter internacional, situación que es una llamada de atención recurrente en el campo de los estudios de migración en los últimos años (Portes, Guarnizo y Landolt 1999; Rumbaut, Foner y Gold 1999; Wimmer y Glick-Shiller 2003). Para ello, hemos tomado un caso específico de 
familias e hijos de una misma comunidad, ya que al centrarnos desde el lugar de origen permite tener "un magnífico ejemplo de la manera en que los estudios de comunidad pueden aportar una dimensión al conocimiento en el tema: la de los protagonistas y su medio en un pueblo de migrantes en un tiempo determinado" (Durand 1991: 14), donde a su vez, se siguió la pista de las familias de origen amequense que se encuentran en el lugar de destino en California.

Aunado a esto, se hizo un seguimiento longitudinal para observar hasta donde han llegado los jóvenes, y examinar las trayectorias educativas de los adolescentes en el lugar de origen y destino; es por ello que realizamos inicialmente el estudio en el 2008 y 2009 en California y Ameca, posteriormente un seguimiento tres años después en California durante abril de 2012, y en agosto y septiembre del mismo año en Ameca. Asimismo, será importante entender los factores que intervienen u obstaculizan el éxito o fracaso profesional en su transición a la adultez, considerando el contexto social, económico, político y cultural donde viven.

\section{Construcción del método, la muestra y sus características}

Para entender el panorama completo de las familias migrantes y no migrantes y los hijos, donde hoy en día los acontecimientos se muestran cada vez más complejos, se requiere un análisis con enfoque interdisciplinario donde se recurra a la antropología y la sociología, disciplinas indispensables para acercarnos a la descripción y el análisis de los factores que intervienen en las trayectorias, donde están en juego aspiraciones, expectativas y logros educativos de los jóvenes que residen en Ameca y de los que viven del otro lado en California.

Es indispensable hacer un acercamiento más completo donde la vida de los migrantes, y no migrantes, pueda ser entendida más allá de los límites del lugar de origen o destino (Levitt y Glick-Schiller 2004: 1003). Es necesario considerar que el estudio deba contemplar el análisis desde ambas comunidades, el origen y destino, para observar el proceso con mayor amplitud. Además, es cada vez más indispensable los estudios que abarcan los distintos momentos del proceso, ya que es importante llevar a cabo ejercicios comparativos entre países que permitan situar adecuadamente los aspectos que se examinan (Ariza y Portes, 2007: 32). Por tal motivo, el trabajo explora las familias y sus hijos que originalmente fueron entrevistados cuando cursaban los grados 7 al 12, mismos que comprenden la educación secundaria y el bachillerato en México, al igual que los hijos que se encontraban cursando los mismos grados en California, equivalentes a la junior high school y la high school.

Nuestro estudio recurre a información etnográfica recogida en trabajo de campo, y a la aplicación de encuestas lo suficientemente amplias para entender cómo se dirigen las trayectorias educativas, y que tanto se separan de las aspiraciones, las expectativas y los logros educativos de los hijos que residen en ambos lados. Por su parte, el trabajo de campo proporciona una visión amplia de primera mano, suministra una base para el establecimiento de la información y además, posibilita formular explicaciones de los resultados previstos y no previstos; por tanto, es la base metodológica de esta investigación. Con el trabajo etnográfico aspiramos a conocer el mundo social de los actores en sus propios términos, para proceder a su explicación, según el marco teórico planteado en nuestra investigación (Guber 2001: 93). Sin embargo, por la complejidad del estudio se hizo acopio de una gran cantidad de datos cuantitativos que actúan como un correctivo a la selectividad del trabajo.

Como etnógrafos, durante el trabajo de campo en California nos sumergimos en la cultura de las familias mexicanas que residen en aquel país. Para ello fue fundamental localizar familias con padres amequenses que tuvieran hijos en escuelas públicas. Se utilizó la técnica conocida como bola de nieve, donde una familia fue proporcionando las coordenadas para localizar a las demás familias. La pieza clave del trabajo etnográfico consistió en vivir y establecerse por varios días con distintas familias en el seno de su propio hogar, tanto en el norte como en el sur de California, pues el objetivo fue comprender y entender la dinámica de la vida familiar, la educación y los elementos característicos del proceso migratorio de cada familia y sus integrantes, en tanto estos elementos juegan un papel central en las 
expectativas y los logros de sus miembros.

El estudio tiene como base cuantitativa principal la encuesta utilizada por Alejandro Portes y Rubén G. Rumbaut para la investigación Children of Immigrants Longitudinal Study (CILS) (Portes y Rumbaut 2005a, 2010, 2011; Rumbaut y Portes 2001). La utilización de la encuesta fue aplicada a padres e hijos en California y Ameca; por un lado se encuestó a los hijos que estudiaban los niveles del 7 al 12 de educación secundaria y bachillerato durante el ciclo escolar 2008-2009. Dicha encuesta recoge datos diversos sobre familia y educación. Por otra parte, se aplicaron encuestas a las familias, contestadas por los progenitores o tutores, las cuales recogen información sobre la educación, características del hogar, crianza de los hijos y migración. Los dos grupos de encuestas se levantaron en ambos lados dentro del mismo ciclo escolar, aunque algunas de las preguntas cambian de acuerdo al contexto local y cultural donde fue realizada la encuesta. Esta estrategia tanto cualitativa como cuantitativa nos permitió obtener información sobre la vida familiar, la migración y la educación desde la perspectiva de los hijos y sus padres. La estrategia fue aplicada en ambos lados de la frontera con la pretensión de analizar una misma comunidad desde varios lugares en distintos países.

\section{Características de la muestra y estructuración del estudio en California y Ameca}

En primer lugar, se realizaron encuestas a familias con hijos en escuelas públicas que cursan el nivel 7 al 12 en las distintas ciudades donde radican las familias migrantes del norte y sur de California. En total se encuestaron a 65 hijos de inmigrantes, quienes forman parte de 40 familias. Los hijos de amequenses asisten a 35 escuelas de nivel básico -Middle School, Junior High y High School- en 14 ciudades, distribuidos en seis condados del estado (véase cuadro 1 y mapa 1).

\section{Cuadro 1}

Familias e hijos entrevistados en las ciudades de los seis condados de California

\begin{tabular}{|c|c|c|c|}
\hline Condados & Ciudades & $\begin{array}{c}\text { Familias } \\
\text { entrevistadas }\end{array}$ & $\begin{array}{c}\text { Hijos } \\
\text { entrevistados }\end{array}$ \\
\hline 1. E1 Dorado & $\begin{array}{l}\text { South Lake } \\
\text { Tahoe }\end{array}$ & 11 & 19 \\
\hline $\begin{array}{l}\text { 2. Stanislaus } \\
\text { 3. Los Angeles }\end{array}$ & $\begin{array}{l}\text { Modesto } \\
\text { Ceres } \\
\text { Los Angeles } \\
\text { Lynwood } \\
\text { Bellflower } \\
\text { Sylmar } \\
\text { San Fernando }\end{array}$ & $\begin{array}{l}9 \\
11\end{array}$ & $\begin{array}{l}13 \\
15\end{array}$ \\
\hline 4. San Bernardino & $\begin{array}{l}\text { Rialto } \\
\text { Ontario } \\
\text { Bloomington }\end{array}$ & 5 & 12 \\
\hline 5. Riverside & $\begin{array}{l}\text { Riverside } \\
\text { Lake Elsinore }\end{array}$ & 3 & 4 \\
\hline 6. Ventura & Oxnard & 1 & 2 \\
\hline Total & 14 & 40 & 65 \\
\hline
\end{tabular}


En segundo lugar, se realizaron encuestas en un primer momento a familias que residen en la cabecera municipal de Ameca con hijos que asistían en escuelas públicas de nivel secundario y bachillerato. El trabajo se llevó a cabo entre abril y agosto de 2009. La selección y búsqueda de las familias se hizo a partir de una muestra de estudiantes de las dos escuelas públicas de nivel secundaria y las dos escuelas de nivel bachillerato (1) que existen en la localidad.

Asimismo, se hizo una selección aleatoria entre todos los alumnos de las cuatro escuelas seleccionadas, después se procedió a la búsqueda de los domicilios de los estudiantes seleccionados y a la aplicación sistemática de cada encuesta, tanto para los alumnos señalados en la muestra, como para los hermanos que se encontraban en alguno de los grados siete al doce del ciclo escolar 2008-2009, y que formaban parte de 90 familias como parte del universo de estudio. En total se encuestaron 114 estudiantes y a su vez a 90 padres de familia (ver cuadro 2). Fueron varios los motivos por los cuales algunas familias e hijos no se les aplicó la encuesta, el más recurrente fue que los alumnos estaban ya dados de baja de la escuela, pese a que aún se encontraban en las listas de asistencia. Otro motivo fue que el alumno que salió sorteado al azar para ser encuestado ya había egresado del bachillerato. Una razón más es que los padres de una familia vivían en Guadalajara; otra más es porque se había mudado a otra ciudad, y un número importante de familias no fueron localizadas en los domicilios proporcionados por las autoridades escolares. Sólo hubo dos casos de familias e hijos que no contestaron la encuesta.

\section{Cuadro 2}

\begin{tabular}{|l|r|}
\hline \multicolumn{2}{|c|}{ Relación de encuestas realizadas en Ameca, Jalisco } \\
\hline Total de estudiantes que forman el universo de la & 3,584 \\
muestra del estudio & 114 \\
Total de estudiantes encuestados para la muestra & 90 \\
Total de familias encuestados & 16 \\
Familias que no se encuestaron por diversos & \\
motivos & 4 \\
Hijos que no contestaron la encuesta & \\
\hline
\end{tabular}

En un segundo momento se realizó un seguimiento longitudinal tres años después, en abril de 2012 en California y durante agosto y septiembre del mismo año en Ameca. Se les preguntó a todos y cada uno de los jóvenes entrevistados en la muestra origen sobre su situación actual educativa y ocupacional, es decir, en qué nivel se encuentran estudiando actualmente, o en su caso, qué actividad están realizando en ese momento. Estas interrogantes nos ayudaron a examinar la trayectoria educativa de los jóvenes, pero además, nos aportan datos importantes para conocer el grado de conexión o desconexión que tienen los jóvenes con las instituciones sociales, dado que existen jóvenes que no estudian ni trabajan, situación que los orilla a una desconexión total de la vida de las instituciones, educativas y/o económicas por las cuales deben transitar. En los Estados Unidos el nivel de desconexión de jóvenes entre 16 y 24 años de edad -es decir, el promedio que no estudian ni trabajan- es un problema social de ascendente magnitud. En 2012, uno de cada siete jóvenes de esa edad (14.7\%, ó 5.8 millones) de jóvenes ni 


\section{El contexto del lugar de origen: Ameca}

La ciudad de Ameca es una población de fácil acceso; cuenta con comunicación directa por carretera desde la ciudad de Guadalajara, capital del estado de Jalisco, de la que dista a $77 \mathrm{~km}$. Ameca se encuentra situada en un extenso valle y sirve como sede en varios aspectos de la vida económica política y social de la región; además, cuenta con una amplia actividad comercial, tanto que abastece las comunidades rurales como la zona urbana del municipio y se encuentra asentada en el extremo oeste del extenso valle. En 2010 el municipio tenía una población total de 57,340 habitantes (INEGI 2010) (2). Por su parte, la población de la cabecera municipal -lugar donde se centra nuestro estudio- concentra casi el $65 \%$ de la población de todo el municipio de Ameca.

Ameca está ubicada dentro de la microrregión cañera del estado, que comprende, los municipios de Ahualulco de Mercado, San Martín de Hidalgo, Teuchitlán y Tala. En esta microrregión se encuentran dos industrias azucareras, el ingenio San Francisco, en Ameca y el ingenio José María Martínez, en Tala; ambos son la base de la economía de la población de estos municipios. En Ameca, además de la caña y el ingenio, también son fundamentales el cultivo del maíz, la ganadería y el sector servicios; todos ellos forman el motor de la actividad económica del municipio.

\section{El contexto social y educativo de los jóvenes en el lugar de origen}

Los servicios educativos que ofrece la ciudad de Ameca a sus residentes y a las poblaciones de las comunidades aledañas es variada en opciones de educación básica, incluyendo dos secundarias públicas de nivel federal y una secundaria privada. También se cuenta con dos escuelas de nivel bachillerato, la Preparatoria Regional de Ameca, de la Universidad de Guadalajara y el Centro de Estudios Tecnológicos e Industriales y de Servicios (CETIS) perteneciente a la Secretaria de Educación Pública. Además, desde septiembre del año 2000, se encuentra dentro del municipio el Centro Universitario de los Valles de la Universidad de Guadalajara, institución que ofrece una gama importante de carreras a nivel universitario (3).

El conteo del 2005 del INEGI reveló que el total de personas de 12 a 14 años que vivían en la cabecera municipal de Ameca era de 2,101, de los cuales 188 no iban a la escuela, lo que representa el $8.9 \%$. Mientras que el total de la población de 15 a 24 años era de 6,404, de los cuales 3,916 no asistían a la escuela, es decir, 61.1\%, lo que representa más de la mitad de los jóvenes en esas edades. En ese sentido, si consideramos al total de los jóvenes y adolescentes que se encuentran en edades de 12 a 14 y de 15 a 24 años que no iban a la escuela, casi la mitad de esa población (48.2\%) no estaba estudiando en los niveles correspondientes a su edad (nivel básico de secundaria, bachillerato y universidad). Estas cifras nos muestran, sin duda, problemas sumamente serios de deserción y abandono escolar, resultado de la incapacidad gubernamental por satisfacer un servicio obligatorio y gratuito a los jóvenes y adolescentes de la localidad (véase cuadro 3).

Asimismo, los porcentajes de la población de 12 a 14 y de 15 a 24 años de edad que no asistían a la escuela nos muestran una situación sumamente adversa, no sólo para los jóvenes y adolescentes de la cabecera municipal de Ameca sino también a nivel estatal y nacional, pues esos porcentajes de no asistencia a la escuela son ligeramente mayores para ambos grupos de edad, en donde la mitad de la población no continúa o abandona la escuela, lo cual confirma la existencia de una situación educativa de crisis profunda, sombría y poco esperanzadora para los jóvenes y adolescentes en México. 
Porcentaje de la población de Ameca de 12 a 14 y de 15 a 24 años de edad que no asiste a la escuela, conteo 2005

\begin{tabular}{|c|c|c|c|}
\hline $\begin{array}{c}\text { Personas de 12 a 14 años } \\
\text { que no van a la escuela }\end{array}$ & $\begin{array}{c}\% \\
\text { Ameca }\end{array}$ & $\begin{array}{c}\% \\
\text { Jalisco }\end{array}$ & $\begin{array}{c}\% \\
\text { México }\end{array}$ \\
\hline $\begin{array}{c}\text { Personas de 15 a 24 años } \\
\text { de edad que no van a la } \\
\text { escuela }\end{array}$ & 61.1 & 11.9 & 9.6 \\
\hline $\begin{array}{c}\text { Personas de 12 a 14 y de } \\
15 \text { a 24 años de edad que } \\
\text { no asisten a la escuela }\end{array}$ & 48.2 & 51.5 & 62.1 \\
\hline
\end{tabular}

Fuente: Elaborado con base en el II Conteo de Población y Vivienda 2005, INEGI.

De acuerdo con los datos obtenidos, los adolescentes y jóvenes de 12 a 14 y de 15 a 24 años de edad que vivían en la cabecera municipal conformaban $24.2 \%$ de la población total de la ciudad; prácticamente una cuarta parte de la población se concentraba en esos grupos de edad, situación que nos habla de la importancia de estos grupos no sólo en términos demográficos, sino también socioeconómicos.

El promedio de escolaridad de la población en la cabecera municipal de Ameca de los que contaban con 15 años y más era de 8.2 grados en general; para los hombres era de 8.5 grados, mientras que para las mujeres de 8.0 grados en promedio. Este porcentaje era similar al del estado (8.2), pero ligeramente superior al nacional (8.1 años de estudio). Por otro lado, si consideramos única y exclusivamente al total de la población de 15 años y más correspondiente a la cabecera municipal, el índice de analfabetismo de la población en ese rango de edad representó $4.9 \%$ (4) sensiblemente menor a lo registrado en todo el estado de Jalisco (5.5\%), pero mucho menor al nivel nacional, situado en $8.4 \%$. Sin lugar a dudas estos datos son muestra de una crisis educativa profunda que impacta y va de la mano de la familia a la escuela y viceversa. Esta situación se presenta casi por igual en los ámbitos local, estatal y nacional, que por consiguiente son resultado de los bajos niveles de capital de desarrollo humano, entre otros factores de carácter estructural, los cuales seguramente impactan la trayectoria de los jóvenes y, por consiguiente, influyen en las expectativas y los logros educativos de los hijos que residen en Ameca.

Los hijos de las familias que forman parte del estudio asisten básicamente a cuatro escuelas, dos secundarias y dos bachilleratos públicos. Estas escuelas se encuentran ubicadas en los cuatro puntos cardinales de la localidad; las dos secundarias se encuentran al norte y sur de la ciudad, mientras que la preparatoria está ubicada al este y el CETIS al oeste, lo cual, de alguna manera, facilita la distribución y el acceso educativo de los jóvenes y adolescentes que habitan en los distintos barrios y colonias de la cabecera municipal de Ameca. Cabe señalar que la mayor distribución en los grados que cursan los jóvenes y adolescentes, tanto en secundaria (grados 7 a 9) como en bachillerato (grados 10 a 12) se concentran mayoritariamente en el tercero de secundaria y el primer año de bachillerato. La tendencia a la baja se concentra entre el segundo y tercer año de bachillerato, lo que indica una paulatina deserción escolar en el bachillerato al paso de los años.

En cuanto a la distribución por sexo de los jóvenes encuestados en Ameca, las mujeres ocupan el porcentaje mayoritario (52.6\%), mientras que los hombres concentran $47.4 \%$. Esta situación refleja el incremento de la participación de las mujeres en el sistema educativo, pero también indica el abandono escolar de los jóvenes varones. Prueba de ello es que los adolescentes varones que cursaban los dos primeros grados de secundaria representaban 55\% de la participación escolar, pero al llegar a los dos 
últimos grados del bachillerato los hombres representaron sólo 38\%. Las mujeres en los primeros años de secundaria representan $45 \%$ y en los últimos años del bachillerato se incrementó su número a $62 \%$, debido fundamentalmente al abandono y deserción escolar de los jóvenes varones.

Aunado a esta situación adversa de abandono escolar y de bajos niveles educativos de los jóvenes que residen en Ameca, y a nivel nacional, a esto se suma que las oportunidades educativas no son suficientes para todos los jóvenes en el país y la apertura al mundo laboral es limitado y precario, pues tan sólo 38\% de los egresados de las cinco carreras más demandadas de la Universidad de Guadalajara encuentran trabajo en su área de especialización y $14.6 \%$ obtiene una vacante para realizar labores afines, mientras que la mayoría (46.6\%) se desempeña en áreas totalmente ajenas a su profesión como el mercado formal e informal (5). En gran medida es resultado del bajo crecimiento económico (1.84\% promedio anual del PIB durante el último sexenio 2006-2012), el más bajo crecimiento desde 1989. Esta situación se centra justo en los años de nuestro estudio (2008/09-2012).

Pero además en México existe un ambiente de inseguridad, miedo y zozobra por una serie de acontecimientos relacionados por un lado por las acciones que ha implementado el crimen organizado como resultado de la guerra contra el narcotráfico, y por el otro, por la respuesta del gobierno del presidente Felipe Calderón hacia estas acciones; ante esto, dicha guerra ha dejado como saldo 80 mil muertos y más de 25 mil desaparecidos (6) según estimaciones conservadoras, que en su gran mayoría son jóvenes entre 18 a 35 años, a lo que podemos señalar que estos sucesos han permeado a todo el norte y occidente del país, incluido el estado de Jalisco, situación que ha obligado a muchos de los jóvenes a verse forzados a involucrarse en actividades ilícitas. Ante esta situación adversa, estructural, de violencia e inseguridad, seguramente repercute en las familias, y sobre todo, en las decisiones individuales de los jóvenes en sus trayectorias educativas de los jóvenes en el país y particularmente en Ameca.

\section{El contexto del lugar de destino y los jóvenes en California}

El contexto sociocultural donde se insertan las familias de Ameca en las distintas ciudades donde residen en California va a permear el desarrollo escolar de los hijos. Es por eso que para entender el proceso de adaptación y desarrollo de sus expectativas y logros educativos, es importante comprender el contexto en el que están insertos. Para ello, es importante primero mostrar de qué manera llegaron los padres a Estados Unidos. La gran mayoría (74\%) de los jefes de familia cruzó la frontera de forma no autorizada, es decir, como indocumentados; $26 \%$ lo hizo de forma autorizada, ya sea como residente permanente 0 con visa de turista. Sin embargo, no todos llegaron al mismo tiempo: sólo el 30\% llegó entre 1973 y 1985, un año antes de la promulgación de la Ley de Reforma y Control de Inmigración (IRCA por sus siglas en inglés), el 50\% lo hizo entre 1986 y la crisis económica de 1994 en México, y sólo el 20\% arribó a Estados Unidos entre 1995 y los primeros meses del 2008.

Debe decirse que además de cruzar la frontera de forma no autorizada, los padres de familia también van con grandes aspiraciones, "esperanzados en una nueva vida más conveniente, aunque esta mejoría en algunos planos signifique vivir bajo la sombra de la xenofobia" (Salas 2011:126). Esta serie de desafíos están presentes en los distintos lugares de residencia donde se establecen las familias de Ameca, tanto en el norte como en el sur de California.

El lugar de residencia de estas familias está dividido en dos zonas geográficas, al norte y sur de California (véase Mapa 1). Al norte del estado se han establecido las familias en varias ciudades, aunque sólo en tres de ellas se ha centrado nuestra atención, ellas son: Modesto y Ceres (7), ubicadas en el Condado de Stanislaus, a solo una hora de distancia al sur de Sacramento, capital del estado. La otra ciudad donde se han establecido los amequenses es South Lake Tahoe (8), lugar que se encuentra a hora y media al noreste de Sacramento, localizada en el Condado El Dorado. 


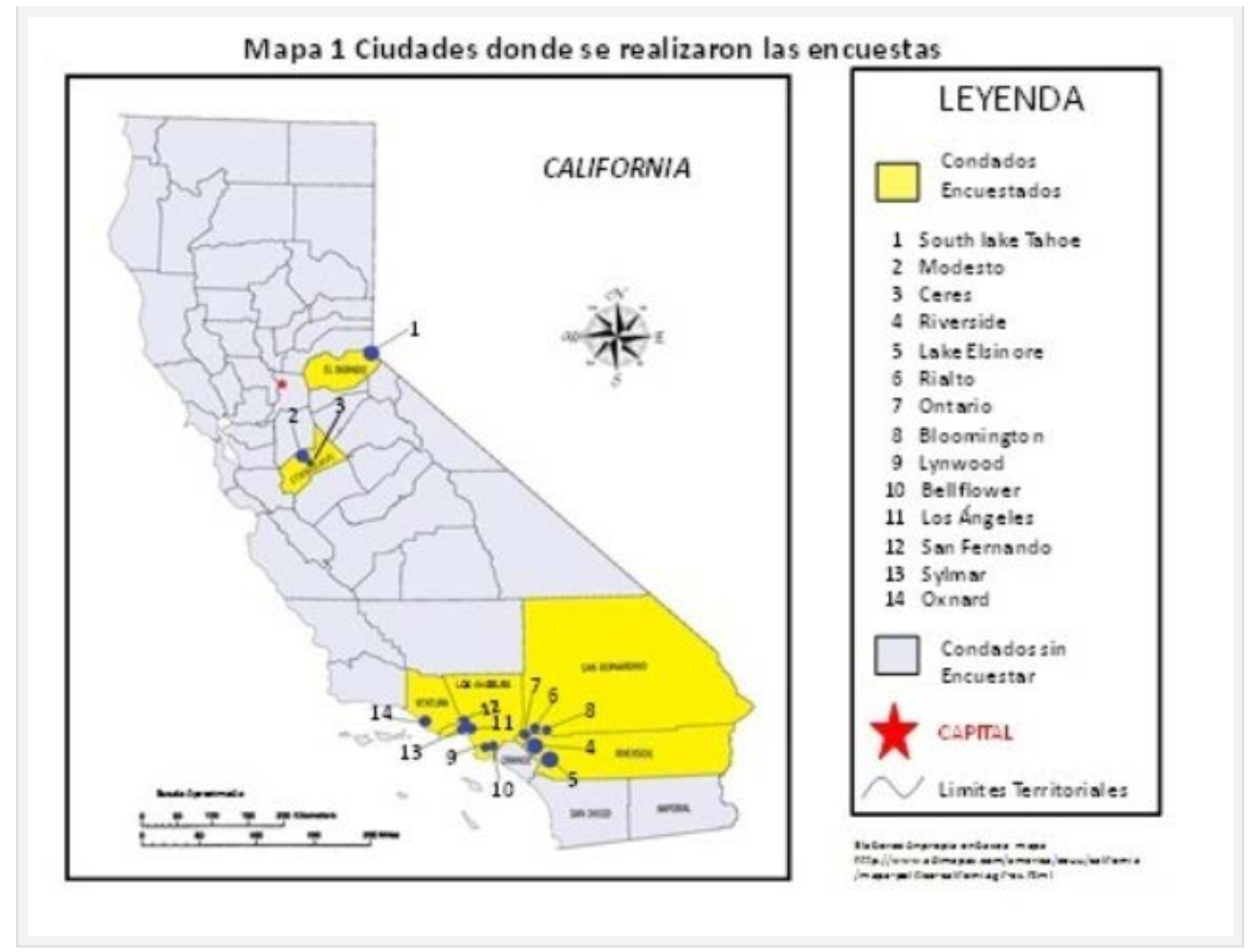

South Lake Tahoe, Modesto y Ceres no cuentan con una amplia infraestructura educativa universitaria como la que existe en el sur del estado. South Lake Tahoe es eminentemente turística por ser una ciudad casino $\mathrm{y}$, las otras dos ciudades son básicamente agrícolas, por lo que carecen de una infraestructura urbana e industrial como la que se cuenta al sur de California. Las tres ciudades no cuentan con una amplia gama de oportunidades para los estudiantes de la high school que desean continuar estudios superiores. Las universidades más cercanas para los estudiantes de South Lake Tahoe se encuentran en Sacramento y Reno, Nevada, y para quienes no deseen bajar de la montaña al finalizar la high school, tendrán que conformarse en continuar estudios preuniversitarios en el Community College de su localidad. Asimismo, la universidad más cercana para los estudiantes de Modesto y Ceres se encuentra en Turlock a treinta minutos de distancia. Modesto es una ciudad agrícola y pobre, quizás una de las más pobres de California (9), y no ofrece posibilidades de mayor acceso universitario. Además, la gama de carreras universitarias en Turlock no es tan amplia como las distintas universidades situadas en el área de Sacramento o en la bahía de San Francisco.

Por su parte, el sur de California es considerado la zona urbana por excelencia en el estado. Aquí se encuentra la ciudad de Los Ángeles, la segunda más grande e importante de Estados Unidos, además de que se concentra la mayor parte de la actividad industrial, cuenta con el mayor número de opciones universitarias tanto públicas como privadas del estado. Las ciudades del sur donde se concentran las familias amequenses están ubicadas principalmente en tres Condados: Los Ángeles, Riverside y San Bernardino, y las ciudades donde viven las familias de origen amequenses son: Riverside, Lake Elsinore, Rialto, Ontario, Bloomington, Lynwood, Bellflower. Este y Centro de Los Ángeles, San Fernando (10) y Sylmar. Las familias residen dispersas por toda la zona urbana de la gran metrópoli. Otras más se localizan en la ciudad de Oxnard (11), dentro del Condado de Ventura, en la zona geográfica del sur del estado. El Condado de Ventura, que es fundamentalmente agrícola, se encuentra contiguo al noroeste de la ciudad de Los Ángeles (véase mapa 1). 
Los distintos lugares de residencia de las familias de Ameca en California responden a distintos factores de asentamiento e incorporación: las redes sociales que han establecido los inmigrantes yla disponibilidad del mercado laboral. El tipo de asentamiento y el modo de incorporación de las familias han sido trastocados por la reciente crisis financiera e hipotecaria del 2007-2010 en Estados Unidos. La crisis en el país fue fácilmente perceptible.

El jueves 30 de octubre del 2008 la ciudad de South Lake Tahoe estaba vacía, se veían pocos autos circulando por las calles, así como poca gente en los restaurantes de la ciudad. No era producto de la temporada baja, periodo en que disminuye el turismo en la ciudad. Esta situación se había presentado desde varios meses atrás, cuya economía se fue desacelerando en el país. La gente ha perdido sus casas, su empleo, aumentó el precio de la gasolina, los productos básicos también aumentaron, había menos trabajo en el sector de la construcción, el campo, los servicios y, en general, en todos los sectores de la economía. Cada vez se presentaba un mayor número de deportaciones de mexicanos y la situación era cada vez más sombría para los inmigrantes indocumentados. Además, la gente señalaba que la economía en sus hogares era cada vez más complicada, lo que se percibía en el consumo y en el estado de ánimo de la población. Incluso todo parecía indicar que lo único que podría cambiar la percepción de la gente era la proximidad de las elecciones presidenciales y el fin del mandato del presidente George W. Bush (2001-2009).

El ambiente sombrío y de desesperanza para los inmigrantes se ha agravado a partir de la gran recesión de 2007-2010. La crisis ha impactado seriamente a las familias de California con una de las tasas de desempleo más altas de la nación, generando una mayor pobreza, que afecta de manera especial a los niños y marginando, aún más, a los inmigrantes en el acceso a un mejor empleo y a las formas básicas de subsistencia, lo que ha lanzado a las familias de inmigrantes a una situación complicada en las decisiones en torno a la educación de los hijos después de la high school. La disminución de las oportunidades para la movilidad ha creado una gran frustración y pesimismo entre la población joven, situación que se acentúa entre los más pobres.

La gran recesión que inició en diciembre del 2007 y se agudizó en septiembre del 2008, ha dejado desempleo y amenaza en la seguridad y la dignidad de millones de personas en Estados Unidos (12); ha sido el peor colapso financiero desde el de 1929. La crisis financiera ha provocado un aumento pronunciado del desempleo (13), pero al derrumbarse el mercado inmobiliario y financiero la pérdida de empleos fue mayor y afectó con más fuerza a los que viven de la manufactura y la construcción; tal es el caso de una gran parte de los inmigrantes que residen en California quienes tienen dominado ese nicho de mercado laboral. Las repercusiones del colapso financiero no se hicieron esperar y la población inmigrante ha sido una de las más golpeadas, por un lado, por la falta de seguro médico, además de la pérdida de sus viviendas y los altos niveles de desempleo y, por otro, la reducción de sus ingresos familiares (14).

Para los padres de las familias de Ameca en California la situación ha empeorado. El 10\% de los jefes de las familias se encontraba en calidad de desempleados y otro porcentaje similar estaba en calidad de trabajador de medio tiempo; además los dueños de negocios y contratistas de la construcción han visto disminuidas sus ventas o, en su caso, se redujeron sus contratos en la construcción (véase cuadro 4). Para el caso de los empleados de tiempo completo el panorama también ha empeorado, ahora son menos las horas que trabajan por semana y más constantes los días de descanso dentro de las empresas donde laboran.

\section{Cuadro 4}

Situación laboral del padre y la madre en California 


\begin{tabular}{|l|r|r|}
\hline & $\begin{array}{c}\% \text { Padres } \\
\mathrm{N}=34\end{array}$ & $\begin{array}{c}\% \text { Madres } \\
\mathrm{N}=40\end{array}$ \\
\hline Trabajador de tiempo & 47.5 & 42.5 \\
completo & 5.0 & 10.0 \\
Trabajador de medio tiempo & 5.0 & 2.5 \\
Desempleado buscando & & \\
trabajo & 10.0 & 2.5 \\
Incapacitado & - & 32.5 \\
Trabaja en el hogar & 10.0 & 7.5 \\
Propietario negocio propio & 7.5 & - \\
Contratista construcción & - & 2.5 \\
Contratista limpieza de casas & 15.0 & - \\
No aplica & 100.0 & 100.0 \\
Total & & \\
\hline
\end{tabular}

La situación también se ha complicado para las madres de las familias de Ameca en California. En el cuadro 4 se observa que sólo $42.5 \%$ de las madres tiene trabajo de tiempo completo, aunque, igual que los padres, tienen recortes en su jornada laboral. Además, $10 \%$ de las madres trabaja medio tiempo y $32.5 \%$ se dedica única y exclusivamente al trabajo del hogar. El número de amas de casa como única ocupación se ha incrementado como resultado del cierre y/o reducción de la producción de varias fábricas manufactureras, empacadoras, empresas dedicadas a los servicios, casinos y hoteles, etc., donde las madres se desempeñan, contribuyendo al ingreso familiar.

En este contexto de recepción, incorporación y desventaja estructural que muchos de los hijos de inmigrantes han encontrado en California, verán que la frustración y el éxito de las oportunidades no pueden ser igualmente percibidas por todos los grupos minoritarios e, incluso, dentro del mismo grupo de inmigrantes y aún más allá dentro de una misma comunidad de inmigrantes mexicanos, como es el caso de las familias de Ameca. Esto ocurre porque las familias y sus hijos emigraron a diferentes momentos y sus modos de incorporación son distintos, dado los periodos en que se insertaron en California, los cuales se pueden dividir en tres momentos: primero antes de IRCA (1973-1985), segundo, el inicio de IRCA y la crisis económica en México durante el gobierno de Carlos Salinas y Ernesto Zedillo (19881994), y por último el periodo entre crisis (1995-2008). Esa situación implica que existan diferencias en la llegada de los padres y por consiguiente en el estatus migratorio de padres e hijos, y a su vez en el lugar donde nacieron los hijos. Así pues, del total de los 65 hijos, 48 de ellos nacieron en Estados Unidos, es decir 73.8\%, quienes forman parte de la segunda generación, y 17 hijos nacieron en México (26.2\%) y forman parte de la generación "uno y medio" (Rumbaut 2006). Sin embargo, para muy pocos la situación del estatus migratorio actual de los hijos ha cambiado: pues casi tres cuartas partes son ciudadanos americanos de nacimiento, mientras que $10.8 \%$ ya cuentan con la residencia permanente y $15.4 \%$ siguen con estatus de indocumentado (véase cuadro 5).

Un tema no investigado con respecto a los mexicanos es el impacto del estatus migratorio de los padres y los hijos en las aspiraciones y el éxito educativo de los hijos en Estados Unidos (Schmid 2001: 77). En este estudio ponemos en contexto el estatus migratorio de los padres y madres de Ameca, escenario que nos ayudará a discutir de qué manera influye y cómo afecta en las expectativas y los logros educativos de los hijos de inmigrantes mexicanos de Ameca, Primero, veamos cuál es el estatus migratorio de los padres. En el cuadro 5 se muestra que 48\% obtuvo la ciudadanía, 26\% de los padres es residente permanente, y $26 \%$ carece de documentos, situación que pone a los hijos de estos últimos en desventaja durante el proceso de incorporación y adaptación en el lugar de residencia. Por su parte, las madres tienen niveles más bajos de estatus legal que los padres: $35 \%$ tiene documentos y $27.5 \%$ ya obtuvo la 
ciudadanía, las madres indocumentadas representan 37.5\%. Esto último se debe a que un gran número de ellas llegaron después de 1989, cuando ya había concluido el proceso de regularización por medio de IRCA. El estatus como indocumentados de padres y madres los pone en desventaja en varios terrenos, puesto que, por un lado tienen los niveles más bajos de ingresos anuales e, incluso, están en condiciones de pobreza; estas familias habían perdido su empleo, su casa y se habían tenido que mudar a un nuevo lugar para vivir con otra familia en hacinamiento.

\section{Cuadro 5}

Estatus migratorio de los hijos, padres y madres en California

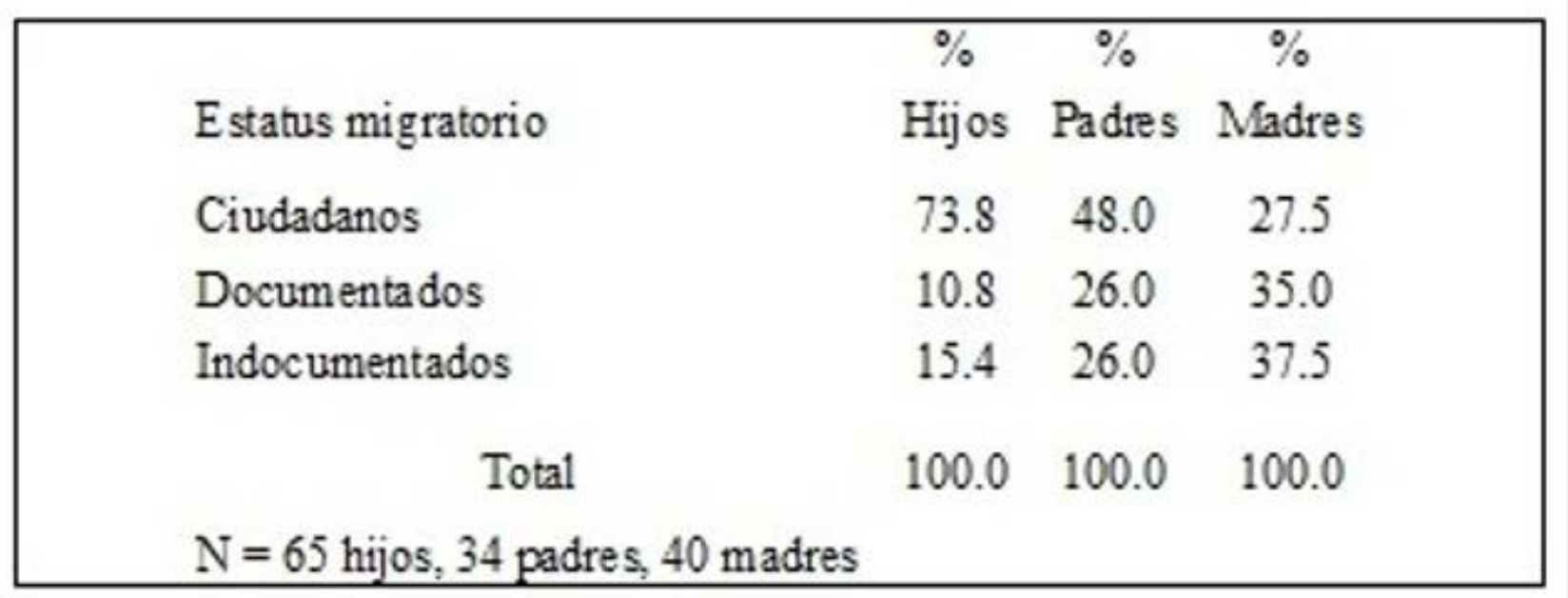

Un gran número de migrantes que vive en Los Ángeles, Modesto y otras ciudades donde viven las familias de Ameca, se quedó sin casa y sin empleo, la situación para muchas familias -principalmente las indocumentadas- se ha vuelto insostenible. Los pagos mensuales de la hipoteca se fueron a niveles impagables para familias que sólo contaban con un ingreso, lo que las obligó a abandonar la casa (15). Las familias tuvieron que mudarse y reestructurar sus finanzas, incluso en muchas de las familias donde los padres son indocumentados se vieron forzadas a repatriarse y volver a empezar en sus lugares de origen, otras no encontraron más salida que el regreso de la madre y los hijos a su pueblo de origen y que el padre se quedara a trabajar en California para enviarles dinero. El panorama es bastante desolador y desesperante, situación que pone a los hijos de inmigrantes indocumentados en un ambiente poco favorable para lograr un rendimiento escolar positivo y, con ello, desarrollar altas expectativas para continuar estudios universitarios.

La información proporcionada por los padres y los hijos nos ha podido constatar que los hijos que viven en familias en condiciones de pobreza son quienes cuentan con un estatus migratorio de indocumentado. Este conjunto de hijos es el más vulnerable y con mayores desventajas en su proceso de adaptación, lo cual no significa que presente expectativas bajas, proceso que veremos a detalle más adelante. El contexto donde se insertan los padres y madres en los distintos lugares donde residen en California ha permeado el desarrollo escolar de los hijos tanto en la familia como en la escuela. Para entender su proceso de adaptación, de las expectativas y de los logros educativos, es importante comprender el contexto en el que ellos mismos se encuentran.

Ahora bien, del conjunto de los 65 hijos entrevistados en el norte y sur de California asisten a 35 escuelas diferentes: cerca del $40 \%$ van a junior high (16), y alrededor de $60 \%$ van a la high school (17). En tanto, $49.2 \%$ de los hijos van a la escuela en el norte de California y $50.8 \%$ atienden la escuela en el sur del estado. 


\section{Efectos de la crisis en la educación en California}

En el terreno de la educación, los hijos de inmigrantes se han visto afectados al interior de las familias, ya que los ingresos han disminuido, lo que ha ocasionado que los hijos cuenten con menos recursos para su educación secundaria y media superior. Esta situación ha dificultado el tránsito a la universidad. Además, los distritos escolares donde están concentrados los inmigrantes mexicanos han sido afectados por la crisis financiera (18) e inmobiliaria, al incrementarse el abandono de las viviendas en los barrios de inmigrantes, y también se debe a que los ingresos que reciben los distritos escolares dependen en buena medida de la plusvalía de las viviendas donde se ubica determinado distrito escolar (19), lo que ha dado como resultado una reducción al presupuesto de los distritos escolares donde habitan los inmigrantes mexicanos y, por consecuencia, una gran desocupación del personal docente, administrativo y de apoyo; sumado a una reducción del calendario escolar y de cursos claves en la high school, así como el aumento de la cantidad de alumnos por clase. Estas son sólo algunas de las mediadas que han implementado los distritos escolares para enfrentar la disminución del presupuesto.

Pero la situación es peor aún en las familias de inmigrantes con hijos en calidad de indocumentados. Tal es el caso de Jorge Curiel, quien llegó a Estados Unidos de forma indocumentada a la edad de seis años junto con sus padres amequenses. Después de nueve años en California sus padres se divorciaron; ahora Jorge vive con su madre, dos hermanos, sus abuelos maternos y tres integrantes más que conforman otra familia y viven en la misma casa, vivienda que cuenta con dos recámaras, una sala comedor y la cocina. Jorge en el año 2008 estudiaba el grado once en la Johansen High School de Modesto; Martha, la madre de Jorge, quiere que él estudie hasta el College. "Yo les he dicho a mis hijos, en este país si quieres vivir bien y tener dinero, no hay otra más que estudiar. A veces, mi hijo no sabe qué hacer para seguir estudiando porque no tiene papeles y eso se le complica más qué hacer, y en momentos dice que mejor se va a ir para México para estudiar allá, porque aquí cuesta mucho dinero estudiar la universidad". Pero Jorge piensa que la única estrategia que tiene para continuar la universidad en Estados Unidos es enrolándose en el ejército para lograr la ciudadanía y después poder entrar a la universidad. El futuro es incierto y la situación económica y familiar es compleja, pues Martha trabaja en el campo y su ingreso es insuficiente para sostener estudios universitarios; además, la condición de indocumentado ensombrece aún más el panorama educativo de Jorge.

La situación de este joven indocumentado hijo de inmigrantes mexicanos es parecida a la de otros jóvenes -entre ellos decenas de amequenses- que llegaron a ese país con sus padres cuando eran pequeños. Estos estudiantes no tienen acceso a préstamos federales o estatales, ni a becas y otros programas para poder ingresar a las universidades públicas (dos tercios de los estudiantes universitarios en este país egresan endeudados para pagar las cada vez más altas colegiaturas en instituciones públicas (20), y no pueden trabajar legalmente para sostenerse mientras estudian. Cada año, según el Urban Institute, alrededor de 65 mil estudiantes indocumentados egresan de la high school de Estados Unidos; de acuerdo con el Migration Policy Institute, los menores de edad conforman 16 por ciento de los 11 ó 12 millones de indocumentados que se calculan están en ese país, o sea 2 millones de estudiantes (21). Ellos los más vulnerables y a quienes prácticamente se les puede considerar como una generación en riesgo, por su calidad de excluidos y falta de esperanza.

\section{Características de las familias en California y Ameca}

Abordaremos primeramente la descripción de las características de las familias de amequenses en California. Cabe decir que la mayoría de los migrantes amequenses residen en el sur de California, principalmente en el área de Los Ángeles, las otras áreas de mayor concentración son: Salinas, San José, San Francisco, Modesto, Vallejo y South Lake Tahoe. Hay otras familias que se encuentran por todo el estado; sin embargo, es interesante señalar que históricamente las familias que provienen de la zona rural de Ameca se han concentrado en las áreas rurales de California y, por el contrario, quienes 
son originarios de la zona urbana han tomado como destino principal la zona metropolitana de Los Ángeles, así como las demás áreas urbanas de la parte norte y sur del estado, con excepción de Modesto, lugar que históricamente ha sido considerado como parte de la extensa zona agrícola del Valle de San Joaquín. Las familias de Ameca que radican en Modesto provienen fundamentalmente del barrio de La Ciénega, ubicado en la cabecera municipal. Sin embargo, pese al potencial agrícola de Modesto, los varones se han insertado, privilegiadamente, en el sector de la construcción, trabajo que los migrantes más añejos aprendieron en el Valle de San Fernando, y las mujeres se desempeñan principalmente en las empacadoras, mejor conocidas como canerías. Por su parte, las familias que se han asentado en Lake Tahoe, tanto en el lado de Nevada como en el de California, provienen de casi todos los barrios de la cabecera municipal y de varias comunidades rurales de Ameca.

Ahora bien, para entender más ampliamente la interacción de la familia y la educación, y de cómo la vida familiar y los factores estructurales impactan en los logros educativos de los hijos, es importante analizar la distribución sexual de los hijos, la estructura familiar o tipo de familia, y el nivel educativo de los padres. En cuanto a la distribución por sexo de los hijos en California de los 65 hijos que forman parte del estudio $38.5 \%$ son hombres y $61.5 \%$ son mujeres (ver cuadro 6). Por su parte, para lograr un mejor análisis en la medición de la complejidad de los distintos tipos de familias y de los arreglos familiares, agruparemos las familias en biparentales y monoparentales o familias sustitutas. Pero además, entendemos a la familia como un punto estratégico para el análisis del cambio en las vidas de sus miembros; la familia es el principal grupo íntimo de reproducción y socialización que frecuentemente sirve para movilizar trabajo, asignar recursos y como agente de comunicación y cambio con otras sociedades (Rumbaut 1997). Asimismo, se entiende la familia como un "crisol de independencia y socialización, con un carácter de conciencia, autoridad y disciplina de los propios integrantes de la misma, donde los une una cadena de sentido y significado" (Rumbaut 1997: 8).

Por lo anterior, es indispensable precisar que las familias que residen en California, a diferencia de las que viven en Ameca, muestran arreglos familiares con una distribución más limitada en su estructura, es decir, son compuestas mayoritariamente por padres biológicos e hijos (83.1\%), definidas como biparentales o "intactas" (Portes y Rumbaut 2010; Rumbaut 2005a). El resto de las familias (16.9\%) son monoparentales, conformadas por la madre y su prole, en otros casos se da cuenta del padrastro u otros familiares o abuelos (véase cuadro 6).

Por otro lado, observamos que las familias que han llegado a un punto de quiebre en su estructura familiar, resultado del divorcio o separación de los padres, son con mayor frecuencia las que se formaron en Estados Unidos. Asimismo podemos ver que las familias que tienden a la unión libre como estatus civil de los padres son las que se formaron en el país del norte. Muchos estudios señalan que la estructura familiar donde ambos padres biológicos viven con los hijos en el mismo hogar es vista como una ventaja para enfrentar las adversidades estructurales (Landale, Thomas y Van Hook 2011; Portes y Rumbaut 2010) y para dar a sus hijos apoyo académico y motivacional, lo que permite fortalecer sus aspiraciones educativas y con ello lograr sus objetivos a largo plazo. Veremos más adelante si esto pareciera ser el caso de las familias de Ameca.

Portes y Rumbaut (2010) señalan, a partir de los estudios empíricos realizados y del análisis que se ha destacado de los hijos de inmigrantes, que no todas las familias poseen los medios para promover el éxito escolar y evitar las amenazas que suponen la discriminación, la reducción de las opciones en el mercado laboral, las bandas callejeras y las drogas. Los recursos para lograr este objetivo son de dos tipos: 1) los que proporcionan el acceso a bienes económicos y oportunidades de empleo, y 2) los que refuerzan el control de normas de los padres. Los padres con altos niveles de capital humano se encuentran, por muchas razones, en una situación mejor para apoyar la adaptación de sus hijos (Portes y Rumbaut 2010, cap. 8).

\section{Cuadro 6}


Distribución de las características principales por sexo del hijo, tipo de familia,

y nivel educativo de los padres en California y Ameca

\begin{tabular}{|c|c|c|c|}
\hline \multicolumn{2}{|r|}{ Caracteristicas de las familias } & $\begin{array}{c}\text { California } \\
\%\end{array}$ & $\begin{array}{c}\text { Ameca } \\
\%\end{array}$ \\
\hline \multirow[t]{2}{*}{ Sexo } & Hombre & 38.5 & 47.4 \\
\hline & Mujer & 61.5 & 52.6 \\
\hline \multirow{3}{*}{$\begin{array}{l}\text { Tipo } \\
\text { familia }\end{array}$} & Biparental & 83.1 & 78.9 \\
\hline & Monoparental o sustituta & 16.9 & 21.1 \\
\hline & 0 a 5 grados & & \\
\hline \multirow{5}{*}{$\begin{array}{l}\text { Nivel } \\
\text { educativo } \\
\text { del padre }\end{array}$} & 6 a 8 grados & 11.8 & 7.5 \\
\hline & 9 a 11 grados & 29.4 & 25.0 \\
\hline & 12 gradost, no terminó & 29.4 & 33.8 \\
\hline & universidad & 20.6 & 26.3 \\
\hline & Universidad o más & 8.8 & 7.5 \\
\hline \multirow{6}{*}{$\begin{array}{l}\text { Nivel } \\
\text { educativo } \\
\text { de la } \\
\text { madre }\end{array}$} & 0 a 5 grados & 15.0 & 15.0 \\
\hline & 6 a 8 grados & 15.0 & 30.0 \\
\hline & 9 a 11 grados & 47.5 & 24.0 \\
\hline & 12 grados + , no terminó & 15.0 & 23.0 \\
\hline & universidad & 7.5 & 8.0 \\
\hline & Universidad o más & & \\
\hline \multicolumn{2}{|l|}{ Total } & 100.0 & 100.0 \\
\hline
\end{tabular}

California: $\mathrm{N}=65$ hijos, 34 padres, 40 madres. Ameca: $\mathrm{N}=114$ hijos, 80 padres, 90 madres.

En el cuadro 6 se muestra que 12\% de los padres no terminó la primaria; 29\% terminó la primaria o menos de secundaria; $29 \%$ finalizó secundaria y hasta once grados; $21 \%$ terminó el bachillerato y algunos años de universidad; y 8.8\% concluyó estudios universitarios en México. En el caso de las madres se observa una tendencia similar entre los primeros grados de estudio y antes de educación secundaria (15\%), 47.5\% tiene de nueve a once grados de estudio, 15\% concluyó bachillerato y algunos años de universidad, y 7.5\% de las madres terminó estudios universitarios en México (véase cuadro 6). Sólo hay tres casos de madres que concluyeron los doce grados de educación en Estados Unidos; uno de ellos es el de Sonia Solano, quien nació en Los Ángeles -hija de padres amequenses- pero vivió unos años en Ameca y otros en California, donde concluyó la high school. Dos madres más continuaron sus estudios en California, Laura Peralta y Ángela Fregoso, quienes llegaron a Estados Unidos con sólo dos grados de estudios de nivel secundaria e ingresaron a la high school para terminar sus educación media básica en aquel país. Esta situación les ha permitido tener un mejor conocimiento del sistema escolar norteamericano y, con ello, un mejor acercamiento en la relación escuela-hijos-padres.

Otro caso interesante es el de Magdalena Uribe, quien emigró a Estados Unidos un par de años después que su esposo Armando García, quien se graduó como profesionista. Ambos salieron en busca de una mejor vida junto con su hijo pequeño y se establecieron en South Lake Tahoe. Nena, como se le conoce en Tahoe, estudió como profesora normalista de educación preescolar en México. Ella sabía que lo 
primero que habría que hacer para tener la posibilidad de desarrollar su profesión en Estados Unidos era aprender inglés y después homologar sus estudios para desempeñarse como educadora. Se enfrentó con una constante discriminación institucional para laborar en una escuela de educación maternal y preescolar. Actualmente, Nena se desempeña como instructora maternal de mujeres adolescentes latinas con embarazos a temprana edad, les brinda ayuda en su proceso maternal mientras concluyen la high school. Ella trabaja principalmente con adolescentes mexicanas.

El nivel promedio de educación de los padres en California es de 9.3 grados de educación, promedio ligeramente inferior al registrado por los padres en Ameca (9.6 grados) y mayor al promedio de los padres de la cabecera municipal de Ameca (8.5 grados). El grado promedio de estudios de las madres en California es 8.9 grados, mayor al de las madres en Ameca (8.5 grados) y de la cabecera municipal registradas por el INEGI en el año 2005 (8.0 grados). Es decir, las madres con hijos en California tienen un grado mayor de educación que las madres no migrantes de Ameca, lo que indica que su selección migratoria es positiva.

Por su parte la distribución por sexo para el caso de los hijos de Ameca se presenta de una forma más equitativa y seguramente eso está relacionado con el método de la selección de la muestra. También en el cuadro 6 podemos observar que la distribución de la estructura familiar en Ameca tienen un porcentaje menor de familias biparentales con respecto a las de California, y a la inversa con las familias monoparentales o sustitutas. Sin embargo, las familias en Ameca uniparentales o sustitutas tienen una característica sustancial, ya que su distribución es mucho más amplia en la conformación de los arreglos familiares, dado que se presentaron varios casos (8\%) donde vive el hijo con los abuelos o con otros tutores, pero sin ningún padre biológico y, ese tipo de conformación familiar no se registró en California.

Siguiendo con los datos mostrados en el cuadro 6 en cuanto al nivel educativo de los padres o tutores varones en Ameca, vemos que existe una distribución diversa: 25\% terminó la primaria, 33.8\% la secundaria, $26.3 \%$ concluyó estudios de preparatoria y $7.5 \%$ estudios universitarios. Por último, sólo uno por ciento no tiene ningún grado de estudios, tal es el caso de un abuelo. Aunque no se muestran estos datos en el cuadro es importante mencionarlos. En cuanto al grado de escolaridad de las jefas de familia, la distribución es más desigual que la de los jefes varones; por un lado, se registran niveles altos de educación universitaria (8\%) pero, por otro, el 5\% de madres no cuenta con ningún grado de estudios: $15 \%$ no terminó la primaria; aunque en secundaria se encuentra la mayoría, con $24 \%$. Por otra parte, el grado promedio de escolaridad de los padres es de 9.5, superior al nivel secundaria, y para el caso de las madres es de 8.5 grados, secundaria inconclusa. Ambas cifras son mayores a las registradas en la cabecera municipal, así como a escala estatal y nacional,

Ahora veamos los logros parciales obtenidos por los hijos en uno y otro lado de la frontera, y su correspondencia con las expectativas expresadas originalmente por ellos mismos, así como qué relación encontramos con las expectativas planteadas por sus padres. En la encuesta se les pidió a los jóvenes que respondieran acerca de sus expectativas educativas, indicándoles, ¿Y realmente cuál es el nivel de educación que piensas obtener?, en ese momento ellos hicieron un reacomodo de sus ideas y evaluaron sus aspiraciones, con algunos cambios importantes, aunque sin modificar drásticamente su perspectiva inicial en su conjunto. Las expectativas de los jóvenes en Ameca que planeaban concluir sólo secundaria representó 3.5\%, mientras que terminar el bachillerato representaron $19.3 \%$, y las expectativas por terminar la universidad $77.2 \%$. Por su parte los hijos que residen en California tenían expectativas de 83.1\% por terminar la universidad, mientras que los que planeaban terminar high school representaron el $16.9 \%$ (véase cuadro 7). Estas cifras mostradas por los hijos de inmigrantes en Estados Unidos son superiores a las de los hijos en México. Esta situación coincide con lo mostrado en otros estudios, donde se ha señalado que las expectativas de los hijos de inmigrantes son mayores a las de los hijos nativos e incluso mayores a las expectativas de los hijos en el país de origen (Kao y Tienda 1995, Feliciano y Rumbaut 2005a).

La misma tendencia ocurre en las expectativas de los padres que viven en California, pues únicamente el $5 \%$ de ellos esperaba que sus hijos concluyan únicamente high school, a diferencia del $26.7 \%$ de los padres en Ameca que planeaban que sus hijos sólo terminen el bachillerato, una diferencia cinco veces 
mayor en México que en Estados Unidos. En cuanto a las expectativas de los padres para que sus hijos concluyan la universidad existe un margen de $14.2 \%$ de diferencia en uno y otro lado de la frontera; mayores son de nueva cuenta las expectativas de los padres de California que los de Ameca (véase cuadro 7). Al respecto habrá que tomar en consideración que los padres en Estados Unidos han aprendido a comparar la forma de vida de su lugar de origen con la del país donde ahora viven; los inmigrantes cuentan con "un doble marco de referencia" (Suárez-Orozco y Suárez-Orozco 1995: 163) lo que les permite tener un referente más amplio de lo difícil que es enfrentar la vida sin una carrera universitaria en ambos lados de la frontera, que los ha llevado a estimular y a hacer reflexionar a sus hijos sobre la idea de que la única opción de progreso que tienen en aquel país es la educación.

\section{Cuadro 7}

Distribución del nivel de expectativas educativas de los hijos en California y Ameca

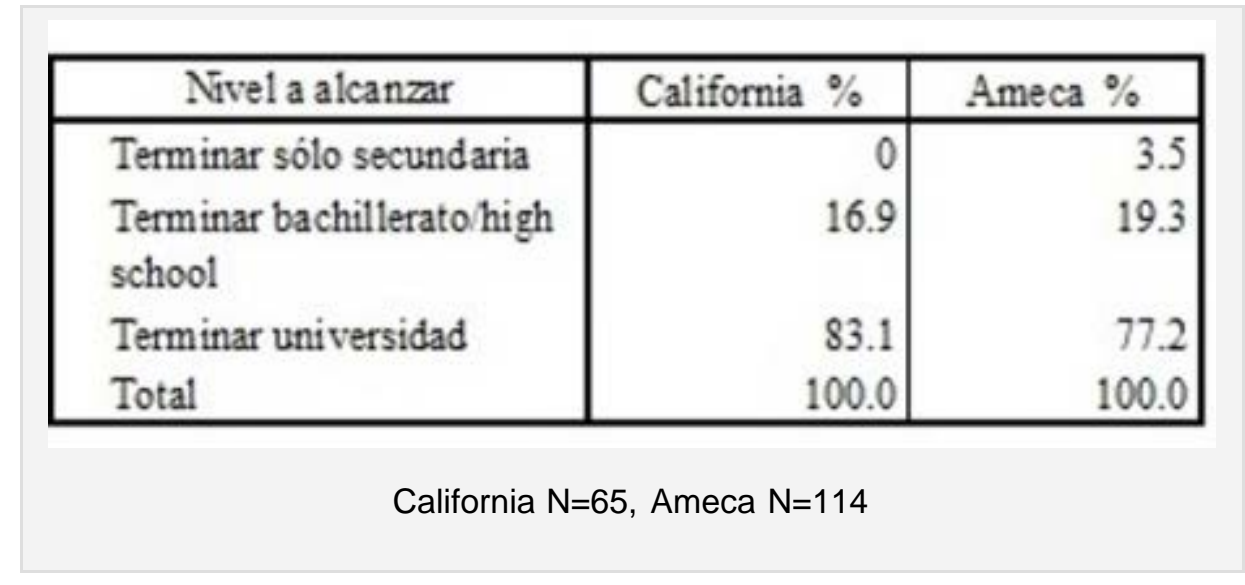

Nivel de expectativas educativas que los padres tienen para sus hijos en California y Ameca

\begin{tabular}{|l|r|r|}
\hline \multicolumn{1}{|c|}{ Nivel a alcanzar } & California $\%$ & Ameca $\%$ \\
\hline Terminar sólo secundaria & 0 & 0 \\
Terminar bachilleratohigh & 5.0 & 26.7 \\
school & 7.5 & \\
Dos años de college & & \\
Terminar universidad & 87.5 & 73.3 \\
Total & 100.0 & 100.0 \\
\hline \multicolumn{2}{|c}{ California $\mathrm{N}=40$, Ameca $\mathrm{N}=90$} \\
\hline
\end{tabular}

Las expectativas educativas que tienen los padres hacia sus hijos que cuentan con nivel bachillerato o menos en Ameca se presenta mayoritariamente en los padres que tienen doce grados o menos de estudio; en algunos casos existe una correlación entre lo que los hijos señalan y lo que sus padres tienen como expectativas hacia sus hijos. Es el caso de Roberto Venegas, Leopoldo Durán y Ramón Hernández, quienes sólo planean estudiar hasta la secundaria o el bachillerato y ellos mismos piensan que sus padres únicamente quieren que estudien hasta el duodécimo grado; lo mismo ocurre con lo que expresaron sus padres sobre el futuro de esos hijos. Son varios los factores que los llevan a plantear esta idea, tanto de tipo socioeconómico como el bajo capital humano que los padres poseen, además de su 
bajo rendimiento escolar, aunado también a la existencia de una atmósfera hostil en casa, la cual limita la comunicación entre padres e hijos y, por tanto, el desarrollo de mayores expectativas positivas.

Las calificaciones reflejan el sentido del rendimiento escolar, pero también son logros escolares que pueden definir decisivamente la dirección del rumbo de las expectativas hacia un futuro no muy lejano de los jóvenes y adolescentes. Veamos el desarrollo y distribución de las calificaciones obtenidas por los hijos en California y Ameca. Antes es importante precisar que los parámetros de calificaciones son distintos en uno y otro lado, es por ello que establecimos cuatro rubros de calificaciones lo más semejante posible con el fin de hacer una correlación de las mismas y establecer una comparación de lo obtenido por los hijos. El cuadro 8 nos muestra que los rubros uno y cuatro tienen ciertas semejanzas pese a que los hijos en California obtienen porcentajes de calificaciones más altas y a la vez menos bajas. Por su parte el contraste se encuentra en los rubros de en medio (dos y tres), aunque de nueva cuenta los hijos en California presentan calificaciones más altas.

\section{Cuadro 8}

Nivel de calificaciones obtenidas por los hijos en California y Ameca

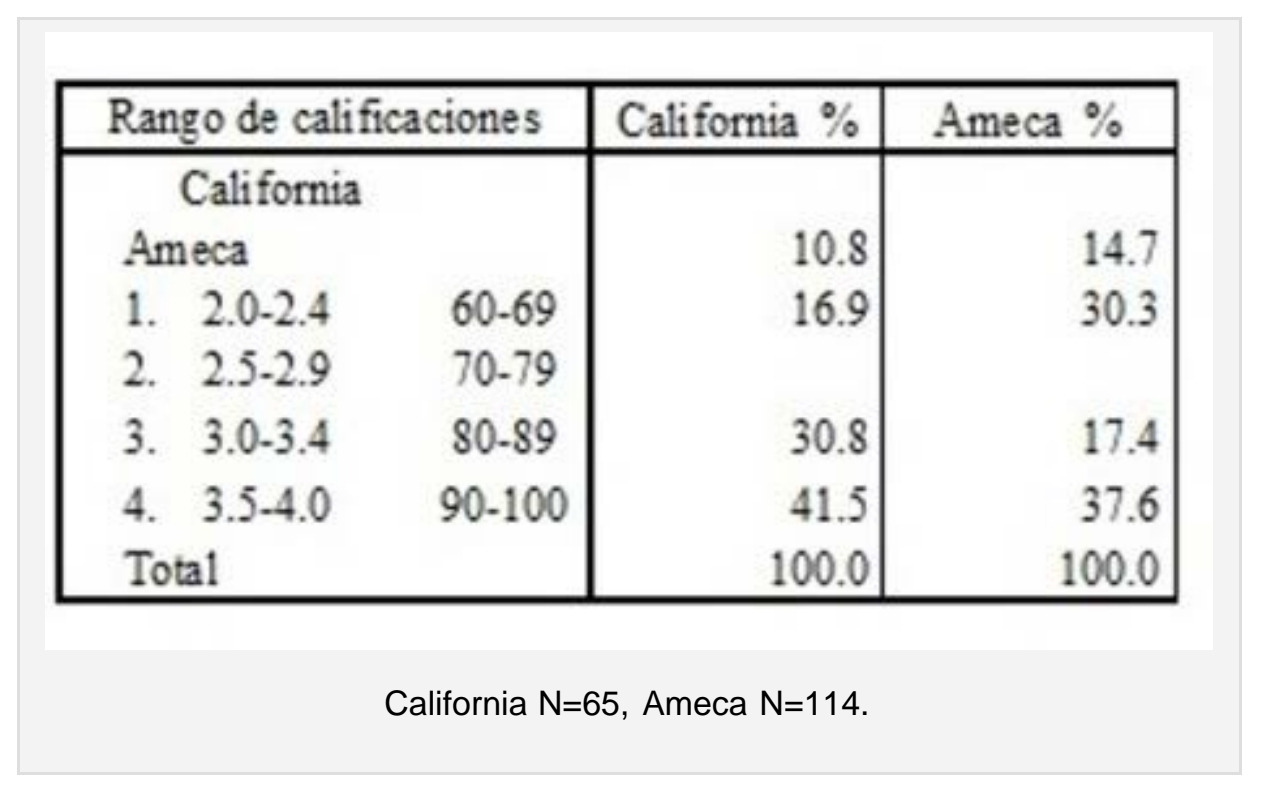

Aunque no en todos los casos las calificaciones de los jóvenes corresponden con las expectativas de los padres hacia sus hijos, tenemos por ejemplo el caso de Soledad Hernández quien vive en Ameca: ella piensa que sus padres tienen expectativas bajas para ella, aunque planea estudiar hasta terminar la universidad, alentada porque su rendimiento escolar es alto, con calificaciones de 96; ella piensa que las limitaciones económicas de la familia y la nula comunicación con sus padres sobre los temas educativos no son favorables para estimular sus aspiraciones, pero pese a esas adversidades, Soledad planea continuar adelante y tiene claro que no desea quedarse atrás como sus hermanos mayores. Tres años después ella continúa estudiando, ahora va en la universidad.

Otro caso interesante es el de Emmanuel Navarro que también vive en Ameca y piensa que sus padres tienen expectativas bajas sobre su futuro educativo; además, las relaciones con su padre no son óptimas para impulsar su progreso escolar. Emmanuel aún estudia la secundaria, y piensa que "si no logro salir en listas en el CETIS, quisiera irme a estudiar a Estados Unidos [...], quiero aprovechar que soy nacido allá y eso ya no sería un problema para mí". Emmanuel piensa que estudiar en aquel país es una posibilidad viable, dado que su padre es pensionado por el gobierno de Estados Unidos y, además, cuatro de sus hermanos mayores viven y trabajan en aquel país. Emmanuel piensa ser abogado y, pese a que sus padres estudiaron sólo hasta tercer grado de primaria, él desea seguir adelante. "Mis papás 
nunca me ayudan en las tareas o lo de la escuela, más bien les pido apoyo a mis amigos. Ellos [sus papás] no pueden ayudarme porque saben muy poco sobre la escuela". A pesar de que Emmanuel enfrenta una serie de adversidades, tiene claro que desea continuar estudiando. Emmanuel finalizó la secundaria con buenas calificaciones y ahora se encuentra en California, allá continúa sus estudios de high school.

Estas breves historias demuestran que los hijos y las familias se enfrentan a una serie de factores que pueden propiciar un clima favorable o desfavorable para estimular u obstaculizar las expectativas educativas en Ameca y California.

\section{Hasta dónde han llegado: determinantes del éxito y el fracaso educativo}

¿Hasta dónde han llegado los jóvenes después de tres años de entrevistados por primera vez en el año 2008 y 2009? ¿Por cuáles caminos han tenido que transitar hacia la adultez? Algunos sueños se han ido cumpliendo pero otros se han roto. Las expectativas planteadas por los jóvenes no siempre corresponden con la realidad que les toca enfrentar. El cuadro 9 nos muestra la distribución de los logros, o en su caso las situaciones por las que se encuentran actualmente los jóvenes y por las cuales han tenido que transitar. Son situaciones establecidas de acuerdo a sus experiencias de vida, aunque no todas se presentan en Ameca y/o California.

\section{Cuadro 9}

Distribución de los logros obtenidos hasta el momento por los hijos en California y Ameca

\begin{tabular}{|l|r|r|}
\hline \multicolumn{1}{|c|}{ Hasta donde han llegado } & California \% & Ameca \% \\
\hline Estudia universidad & 41.5 & 23.7 \\
Estudia high school bachillerato & 41.5 & 25.4 \\
Estudia y trabaja & - & 4.4 \\
Trabaja & 9.3 & 22.8 \\
Desconecta do (ni estudia ni tra baja) & 4.6 & 17.5 \\
Emigró a Estados Unidos & - & 3.5 \\
Emigró a México (retornó a & 3.1 & - \\
México) & - & 1.8 \\
Migración interna & - & .9 \\
Falleció & & \\
Total & 100.0 & 100.0 \\
\hline
\end{tabular}

California $\mathrm{N}=65$, Ameca $\mathrm{N}=114$.

Primeramente cabe destacar el gran porcentaje (83\%) de jóvenes en California que continúan estudiando en niveles de universidad o high school (22), pese a las dificultades estructurales, políticas, y a las que enfrentan al interior de cada familia inmigrante ya enunciadas líneas arriba. Mientras tanto sus padres en Ameca tienen un panorama mucho más desolador, pues sólo un poco más de la mitad continua estudiando los mismos niveles (véase cuadro 9).

Los jóvenes señalados con la etiqueta de "trabaja", significa que ninguno de ellos estudia a la vez la 
universidad y, para el caso de Ameca, tampoco continuaron el bachillerato o abandonaron la escuela antes de terminar la secundaria, por lo que optaron por trabajar. Esta situación es dos veces mayor en Ameca que en California. La etiqueta de "estudia y trabaja" sólo se presenta en los jóvenes de Ameca, y sólo uno de esos casos se encuentra ya en la universidad y además trabaja; el resto aún cursa el bachillerato (véase cuadro 9). Es importante señalar que los trabajos que desempeñan los jóvenes en Ameca son sumamente precarios, de muy bajo perfil y por tanto, mal remunerados.

Los jóvenes entre 16 y 24 años que no estudian ni trabajan (23) más que una etiqueta forman una realidad social: Ios desconectados. Las instituciones sociales -como la escuela y el mercado laboral- no tienen cabida para todos en ambos países, y no son capaces para enrolarlos, así que miles y millones de jóvenes se han visto orillados a ser desconectados del mundo educativo y laboral (Burd-Sharps y Lewis 2012). Para nuestro caso de estudio los desconectados que se muestran en el cuadro 9 presentan dos situaciones reveladoras. Por un lado, los jóvenes de padres mexicanos que residen en California y que tienen un mismo origen, Ameca, tienen niveles mucho menores (apenas el 4.6\%) que los presentados en el estudio One in seven de Burd-Sharps, y Lewis, quienes señalan que la media de desconectados a nivel general en Estados Unidos es de $14.7 \%$ y de $18.5 \%$ para los latinos, porcentajes mucho más altos que el de los jóvenes amequenses en California. Estos datos de nuestro estudio revelan que no es posible tratar a todos los grupos nacionales por igual, e incluso dentro del mismo grupo nacional y comunitario, puesto que los hijos de inmigrantes tienden hacer su mayor esfuerzo por adaptarse y salir adelante en una sociedad ajena a la de sus padres.

En Ameca, los jóvenes que no estudian ni trabajan (17.5\%) tienen niveles muy cerca y por debajo de los que sí se desempeñan en el mercado laboral (véase cuadro 9). El contexto de los jóvenes desconectados en México es tal vez mucho más complejo que en Estados Unidos; las variantes y razones que orillan a su desconexión son mucho más confusas y a la vez parecen más simples. Sin embargo cada joven tiene una razón individual; por ejemplo, hay quienes abandonan la escuela porque fueron expulsados por distintos motivos y no pueden ser instalados en otra escuela, pero tampoco pueden trabajar. Hay otros que se ven orillados a desertar de la escuela para ponerse a trabajar porque la situación económica familiar es más apremiante que educarse, más sin embargo, no encuentran trabajo. Además el ambiente de inseguridad producto de la guerra contra el narcotráfico ensombrece el panorama. Aquí cabe señalar que dos de los jóvenes en Ameca etiquetados como desconectados están involucrados en actos ilícitos como la venta de droga.

Son varios los caminos y emigrar al norte es uno de ellos: cuatro de los casos (3.5\%) tuvieron que salir de su pueblo para buscar una mejor vida. Los cuatro casos contaban con documentos legales para internarse en aquel país del norte. Pero retornar a México de California -como vemos en $3.1 \%$ de los casos- es otro camino por transitar: la no adaptación a la sociedad norteamericana y las deportaciones forzadas se enfrentan a los sueños de familias y jóvenes inmigrantes (véase cuadro 9).

Mudarse al interior de México es otro tránsito en la vida, no tanto bajo la voluntad de los jóvenes; casi siempre el trabajo de los padres dirige los destinos de residencia de los hijos. El 1.8\% señalado en el cuadro 9 corresponde a dos casos de jóvenes quienes tuvieron que abandonar el pueblo junto con su familia e irse a vivir donde el padre fue enviado, uno como gerente de banco y otro que fue solicitado en otra unidad militar. Los jóvenes tendrán que rehacer su vida en otra parte del país. Sin embargo, el peor camino para todo adolescente a esa temprana edad -el dejar de existir- fue el caso de una joven de Ameca que formaba parte de nuestro universo de estudio.

Cuando observamos la división por sexo de los jóvenes en California y Ameca, hemos observado que hay trayectorias distintas (véase cuadro 10). Las mujeres han tenido más éxito educativo que los hombres en ambos países, y los hombres se insertan de forma más temprana al mercado laboral, aunque con empleos más precarios. Sin embargo, las mujeres de Ameca registran el mayor porcentaje de desconexión social -no estudian ni trabajan- y en California las mujeres son las únicas con niveles de desconexión. Los datos mostrados en el cuadro 10 nos revelan que existe una correlación con lo expuesto en el estudio One in seven de Burd-Sharps y Lewis (2012), quienes señalan que las mujeres latinas en Estados Unidos son quienes registran los mayores niveles de desconexión por sexo y grupo 
racial o étnico.

\section{Cuadro 10}

Distribución de las trayectorias y los logros educativos de los hijos por sexo en California y Ameca

\begin{tabular}{|l|r|r|r|r|r||}
\hline \multirow{2}{*}{ Sexo hijo } & \multicolumn{5}{|c||}{ Hasta donde han llegado los hijos en California } \\
\cline { 2 - 6 } & $\begin{array}{c}\text { Estudia } \\
\text { unirvesidad }\end{array}$ & $\begin{array}{c}\text { Estudia high } \\
\text { school }\end{array}$ & \multicolumn{1}{c||}{ Trabaja } & Desconectado & $\begin{array}{c}\text { Emigró a } \\
\text { Mex ico }\end{array}$ \\
\hline Hombre & $36.0 \%$ & $44.0 \%$ & $20.0 \%$ & & \\
\hline Mijer & $45.0 \%$ & $40.0 \%$ & $2.5 \%$ & $7.5 \%$ & $5.0 \%$ \\
\hline Total & $41.5 \%$ & $41.5 \%$ & $9.2 \%$ & $4.6 \%$ & $3.1 \%$ \\
\hline
\end{tabular}

$N=65$

\begin{tabular}{|l|r|r|r|r|r|r|r|r||}
\hline \multirow{2}{*}{} & \multicolumn{7}{|c||}{ Hasta donde han llegado los hijos en Ameca } \\
\cline { 2 - 9 } Sexo hijo & $\begin{array}{l}\text { Estudia } \\
\text { Universidad }\end{array}$ & $\begin{array}{c}\text { Estudia } \\
\text { Bachillerato }\end{array}$ & $\begin{array}{c}\text { Estudia } \\
\text { y rabaja }\end{array}$ & Trabaja & Desconac tado & $\begin{array}{c}\text { Emigró a } \\
\text { Estados } \\
\text { Unidos }\end{array}$ & $\begin{array}{c}\text { Migración } \\
\text { intema }\end{array}$ & Falleció \\
\hline Hombre & $20.4 \%$ & $24.1 \%$ & $3.7 \%$ & $37.0 \%$ & $7.4 \%$ & $3.7 \%$ & $3.7 \%$ & \\
\hline Mujer & $26.7 \%$ & $26.7 \%$ & $5.0 \%$ & $10.0 \%$ & $26.7 \%$ & $3.3 \%$ & & $1.7 \%$ \\
\hline Total & $23.7 \%$ & $25.4 \%$ & $4.4 \%$ & $22.8 \%$ & $17.5 \%$ & $3.5 \%$ & $1.8 \%$ & $.9 \%$ \\
\hline
\end{tabular}

$\mathrm{N}=114$

Es más alarmante lo que se observa en México con los niveles de desconexión de las mujeres, aunque a base de las encuestas no es posible determinar las razones de su desconexión. Para ello hemos recurrido a la etnografía -el trabajo de campo- que nos ha permitido observar que factores tanto estructurales como del entorno familiar orillan a las mujeres a no trabajar y no estudiar. El hecho que las instituciones públicas (universidad y bachillerato) no tienen cupo para todos los jóvenes en México es uno de los factores determinantes de su desconexión; por otro lado, los embarazos a temprana edad conllevan a las jóvenes y adolescentes a quedarse inhabilitadas en términos del mundo educativo y laboral. Lo aquí expuesto indica que el sexo sí es un factor determinante en la trayectoria de los jóvenes hacia la adultez.

La distribución de las trayectorias hacia la adultez en los jóvenes por estatus migratorio en California, nos muestra situaciones relevantes, y tal vez la más importante es que los jóvenes con estatus migratorio de indocumentado son quienes muestran un mayor porcentaje -con relación a sus pares en calidad de documentados o ciudadanos estadounidenses- que ahora se encuentran estudiando en la universidad: $60 \%$ vs. $38 \%$ (véase cuadro 11). Otro aspecto relevante es que para los jóvenes indocumentados en Estados Unidos no hay cabida para estar desconectados de las instituciones sociales como la escuela o el mercado laboral, dado que no hay ningún caso de jóvenes en estas circunstancias. Paradójicamente, 
las condiciones adversas -tanto económica como no autorizada en su situación migratoria- de las familias no permite una desconexión del mundo social para los jóvenes. Sin duda, una variable importante que fue posible observar y que empuja a los jóvenes a seguir adelante para lograr el éxito educativo, está relacionada con la estrecha relación del padre varón con los hijos en las familias donde el padre es indocumentado.

\section{Cuadro 11}

Trayectorias y logros educativos de los hijos por estatus migratorio en California

\begin{tabular}{|l|r|r|r|r|r|r|}
\hline & \multicolumn{5}{|c|}{ Hasta donde han llegado los hijos en California } & \\
\cline { 2 - 6 } Estatus migratorio hijo & $\begin{array}{c}\text { Estudia } \\
\text { Universidad }\end{array}$ & $\begin{array}{c}\text { Estudia high } \\
\text { school }\end{array}$ & Trabaja & Desconectado & $\begin{array}{c}\text { Emigró a } \\
\text { México }\end{array}$ & \multirow{2}{*}{ Tola1 } \\
\hline Docum/Ciudadano & $38.2 \%$ & $43.6 \%$ & $9.1 \%$ & $5.5 \%$ & $3.6 \%$ & $100.0 \%$ \\
Indocumentado & $60.0 \%$ & $30.0 \%$ & $10.0 \%$ & & & $100.0 \%$ \\
Total & $41.5 \%$ & $41.5 \%$ & $9.2 \%$ & $4.6 \%$ & $3.1 \%$ & $100.0 \%$ \\
\hline
\end{tabular}

$\mathrm{N}=65$

Vale la pena mencionar que los jóvenes de nuestro universo de estudio en California, hijos de inmigrantes nacidos en México, mayoritariamente indocumentados, no se han visto envueltos en situaciones de pandillerismo o que cuenten con antecedentes penales. Esto muestra una correlación directa con los hallazgos presentados por Rumbaut (2005b), quien señala que los hijos de inmigrantes latinos nacidos en el extranjero son quienes muestran los niveles más bajos de encarcelamiento con respecto a los nacidos en Estados Unidos.

\section{Conclusiones}

El planteamiento de una estrategia metodológica que nos permita movernos entre el origen y el destino, viéndolo como un todo y no como entes separados, nos ha podido acceder a la información y a los actores principales de nuestro estudio, pero, sobre todo, nos ha permitido acercarnos a observar detenidamente las trayectorias educativas de los jóvenes en ambos lados de la frontera entre México y Estados Unidos. De tal manera, que estudiar desde el origen nos permitió comprender de forma más amplia hasta donde han llegado los jóvenes que viven y se quedaron en Ameca y los que se fueron y nacieron del otro lado de la frontera en California.

En términos generales lo logrado en el terreno educativo tiene una correlación directa con las calificaciones obtenidas y las expectativas mostradas por los jóvenes, aunque desde luego los factores estructurales y del entorno familiar obstaculizan y rompen con los sueños que tienen los jóvenes por llegar a la universidad. Es a partir de nuestros hallazgos que podemos constatar que el sistema escolar mexicano complica el rumbo más positivo hacia la adultez de los jóvenes de Ameca, ya que parece poner en una encrucijada a los jóvenes, presumiblemente de las clases bajas. Allá el sistema escolar no proporciona las oportunidades suficientes ni las herramientas necesarias para tener éxito profesional, para "salir adelante" en su vida adulta; además, los jóvenes se enfrentan a ambientes familiares poco propicios en la transmisión del capital cultural en sus hogares. 
Es fundamental mostrar y entender el mundo educativo de los hijos de inmigrantes mexicanos que residen en California, ya que de acuerdo con los logros académicos obtenidos hasta el momento por los hijos de padres inmigrantes de Ameca, es posible concluir que estos hijos de inmigrantes mexicanos no son tan diferentes de aquellos con padres nacidos en Estados Unidos de otros grupos raciales, quienes en gran medida son influenciados por el estatus socioeconómico familiar y por el nivel socioeconómico promedio de sus escuelas y más aún por el estatus formal de ciudadano americano.

Los resultados positivos aquí presentados de las familias y los hijos de inmigrantes provenientes de Ameca que residen en California, en contraparte con los resultados arrojados por Portes y Rumbaut en su estudio CILS, ponen en evidencia que un sector de familias mexicanas ha ido aprendiendo el valor sustancial de la educación como un mecanismo de movilidad económica para un mejor futuro de los hijos. Las familias mexicanas han tardado muchos años en atender la importancia de la educación en la sociedad norteamericana, pero a partir de la búsqueda por establecer un nuevo proyecto de vida familiar e individual en el país de acogida, y de que los padres inmigrantes mexicanos saben que ya no regresarán a México, ha derivado en que tomen conciencia de que la única manera de llevar a sus hijos adelante es a través de la educación. Por lo visto la educación es lo que cambiará para bien las trayectorias de vida de los que se van y los que se quedan.

La inserción positiva de los hijos de inmigrantes indocumentados (Dreamers) (24) de Ameca es sólo una muestra de que los dreamers en Estados Unidos están cumpliendo sus sueños por adaptarse positivamente a la sociedad norteamericana. Eso merece una oportunidad para que sea legalizado su estatus migratorio. El Dream Act es un proyecto de ley ante el Congreso estadounidense que crearía un camino a la ciudadanía formal para los jóvenes que se encuentran no autorizados, y así poder avanzar en la escala social a partir de la obtención del éxito educativo, situación que podría contribuir de mejor manera en el desarrollo de la economía y de la sociedad en aquel país.

\section{Notas}

1. Las cuatro escuelas son: Secundaria Pública Federal José María Morelos y Pavón, Secundaria Pública Federal José María Luis Mora, Centro de Estudios Tecnológicos y de Servicios CETIS y la Preparatoria Regional de Ameca.

2. Instituto Nacional de Estadística Geografía e Informática de México.

3. Las licenciaturas que ofrece el Centro Universitario son: Licenciado en Administración, Agro negocios, Derecho, Contaduría, Educación, Electrónica y Computación, Informática, Mecatrónica, Nivelación de Enfermería, Sistemas de Información, Psicología y Turismo.

4. Históricamente, la baja en los índices de analfabetismo en este sector de la población de jóvenes y adolescentes ha ido notoriamente descendiendo, al mismo tiempo que el promedio de escolaridad se ha incrementado.

5. Las cinco de las diez carreras más demandadas en la universidad son: Derecho, Psicología, Arquitectura, Administración y Contaduría. Información tomada del Observatorio Laboral de la Secretaria del Trabajo y Previsión Social, 2012.

6. Revela The Washington Post lista de PGR con 25 mil desaparecidos en el sexenio, La Jornada 1 de diciembre de 2012: 17 .

7. La población estimada para la ciudad de Modesto en julio del 2008 era de 202,967, y para Ceres 42,690, habitantes. 
8. La población estimada en el 2008 para la ciudad de South Lake Tahoe era de 23,333 habitantes. http://www.city-data.com/city/South-Lake-Tahoe-California.html [consulta 13 de mayo de 2011].

9. Modesto es una ciudad agrícola y pobre, tal vez una de las más pobres del estado de California, que fue clasificada en 2006 en el puesto 16 de las áreas metropolitanas más peligrosa del país y en el 39 en 2008. En 2009, la revista Forbes clasificó a Modesto como la peor área metropolitana del país, meses después, fue clasificada como la quinta ciudad más miserable de Estados Unidos. (Fecha de consulta 13 de mayo de 2011).

10. La población estimada para Riverside en el 2008 era de 295,357 habitantes, Lake Elsinore contaba con una población de 50,952 Rialto $(98,700)$ Ontario $(171,691)$ Bloomington $(22,504)$ Lynwood $(70,025)$ Bellflower $(73,33)$ Los Ángeles $(3,383,995)$ y San Fernando $(23,833)$.

http://www.city-data.com/city/California2.html [consulta 13 de mayo de 2011].

11. La población estimada para Oxnard en el 2008 era de 185,717 habitantes. http://www.city-data.com/city/California2.html [consulta 13 de mayo de 2011].

12. Para mayor información véase el documental Capitalismo una historia de amor de Michael Moore sobre los efectos de la crisis financiera en Estados Unidos.

13. Los niveles de desempleo en 2008 fueron de 4.6\% mientras que en 2009 llegó a 7.2\%, por su parte los niveles de crecimiento en 2008 fueron de 2\% y en 2009 fue apenas del 1.1\%. Citado en http://www.indexmundi.com/g/g.aspx?c=us\&v=74 [consulta 15 de mayo de 2011].

Esta situación orilló a miles de familias inmigrantes a solicitar ayuda al Programa Woman, Infant and Children (WIC). The New York Times reveló que "unos 6 millones de estadunidenses sortean la crisis únicamente con vales oficiales que son canjeados por alimentos, sin ningún ingreso en efectivo". La Jornada 4 de enero de 2010.

14. Esta situación orilló a miles de familias inmigrantes a solicitar ayuda al Programa Woman, Infant and Children (WIC). The New York Times reveló que "unos 6 millones de estadunidenses sortean la crisis únicamente con vales oficiales que son canjeados por alimentos, sin ningún ingreso en efectivo". La Jornada 4 de enero de 2010.

15. Como un dato interesante sobre el drama de la crisis hipotecaria en Estados Unidos, la foto ganadora del premio internacional para el género de fotoperiodismo Word Press Photo 2008, fue otorgada al fotógrafo norteamericano Anthony Suau. La imagen muestra un oficial armado del Departamento del Sheriff del Condado de Cuyahoga inspeccionando un hogar de Cleveland, Ohio, siguiendo el desalojo producido por un vencimiento hipotecario. "La fuerza de la fotografía esta en los contrastes. Parece una foto de guerra, pero no se trata más que de la expulsión de los ocupantes de una casa... Ahora la guerra está en casa porque no puede pagar las hipotecas", dijo la presidenta del jurado Mary Anne Golon. La imagen ganadora fue tomada en marzo del 2008, es parte de una historia encargada por la revista Time. La historia completa ganó el Segundo Premio en la categoría del concurso Vida Cotidiana.

16. Las escuelas middle school atienden los grados seis, siete y ocho y la junior high los grados siete y ocho.

17. La high school atiende los grados nueve, diez, once y doce de educación media básica en Estados Unidos.

18. Según la Asociación de Maestros de California, en los últimos dos años el presupuesto de Educación del estado tuvo una reducción de 17 mil millones de dólares. Citado en el periódico virtual Latino California.

http://www.latinocalifornia.com/site/ 
19. Las fuentes de financiamiento para las escuelas de California de nivel secundaria son: estatal $52.8 \%$, federal $14 \%$, local $32 \%$ y de la lotería $1.2 \%$. Lo referente a lo local se deriva de los impuestos recabados por la ciudad y por la plusvalía de las viviendas.

http://translate.google.com.mx/translate?hl=es\&langpair=en\%7Ces\&u=http://www.cde.ca.gov/fg/fr/eb/ [consulta 15 de mayo de 2011].

20. Una nota que apareció en Russia Today (4/9/10) expone en forma dramática la deuda impagable de los estudiantes desamparados para pagar su educación, que los cataloga de esclavos laborales debido al "adeudo de más de 830 mil millones de dólares y quienes, para colmo de males, han sido los más desprotegidos y perjudicados por el galopante desempleo", como consecuencia de la crisis financiera en Estados Unidos. La Jornada 8 de septiembre 2010.

21. La Jornada el 18 de junio de 2010.

22. Del $41.5 \%$ que estudia el college o la universidad existe un solo caso donde ya concluyó sus estudios de enfermera y ahora trabaja como profesionista en esa área en Los Ángeles, California.

23. Los jóvenes que No estudian Ni trabaja han sido señalados como (Ninis) categoría utilizada en México preferentemente de corte periodístico.

24. Para mayor detalle véase la nota periodística de Nora Peterson, "Young Immigrants Say It's Obama 's Time to Act", publicado en el The New York Times el 30 de noviembre de 2012.

\section{Bibliografía}

Ariza, Marina (y Alejandro Portes)

2007 "La migración internacional de mexicanos. Escenarios y desafíos de cara al nuevo siglo", El país trasnacional migración mexicana y cambio social a través de la frontera, Marina Ariza y Alejandro Portes (coords.). México, IIS-UNAM, 11-47.

Burd-Sharps, Sarah (y Kristen Lewis)

2012 One in Seven: Ranking Youth Disconnection in the 25 Largest Metro Areas. New York, Measure of America, Social Science Research Council.

Durand, Jorge

1991 Migración México-Estados Unidos. Años veinte. México, CONACULTA.

Feliciano, Cynthia (y Rubén G. Rumbaut)

2005 "Gendered Paths: Educational and Occupational Expectations and Outcomes among Adult Children of Immigrants", Ethnic and Racial Studies 28, 6: 1087-1118

Guber, Rosana

2001 El salvaje metropolitano. Buenos Aires, Paidós.

Instituto Nacional de Estadística Geografía e Informática. México, II Conteo de Población y Vivienda 2005.

Instituto Nacional de Estadística Geografía e Informática. México, Censo de Población y Vivienda 2010.

Kao, Grace (y Marta Tienda)

1995 "Optimism and Achievement: The Educational Performance of Immigrant Youth", Social Science Quarterly, no 76: 1-21.

Landale, Nancy S. ( Kevin J. A. Thomas y Jennifer Van Hook) 
2011 "The Living Arrangements of Children of Immigrants", The Future of Children, Vol. 21, n 4: 43-70.

Levitt, Peggy (y Nina Glick Schiller)

2004 "Conceptualizing Simultaneity: A Transnational Social Field Perspective on Society", International Migration Review 38, n 3: 1002-1039; versión en español "Perspectivas internacionales sobre migración: Conceptualizar la simultaneidad”, Migración y desarrollo, Vol. 3: 60-91.

Portes, Alejandro (Luis E. Guarnizo y Patricia Landolt)

1999 "The Study of Transnationalism: Pitfalls and Promise of an Emergent Research Field", Ethnic and Racial Studies, $\mathrm{n}^{\circ} 22,2$.

Portes, Alejandro (y Rubén G. Rumbaut) 2005 The Second Generation in Early Adulthood. Número especial de Ethnic and Racial Studies, $\mathrm{n}^{\circ} 28$, 6.

2010 América Inmigrante. Anthropos, Barcelona.

2011 Legados: La Historia de la Segunda Generación Inmigrante. Hipatia, Barcelona

Portes, Alejandro (y otros)

2011 "Dreaming in Spain: Parental Determinants of Immigrant Children's Ambition." CMD Working Paper 11-02b. Center for Migration and Development, Princeton University.

Rumbaut, Rubén G.

1997 "Ties that bind: Immigration and immigrant families in the United States", en Alan Booth, Ann C. Crouter y Nancy Landale (ed.), Immigration and the Family. Laurence Erlbaum Associates Inc.: 3-46.

2005a "Children of immigrants and their achievements", en Ronald D. Taylor (ed.), Addressing the Achievement Gap: Findings and Applications. Information Age Publishing: 23-59.

2005b "Turning points in the transition to adulthood: Determinants of educational attainment, incarceration, and early childbearing among children of immigrants", Ethnic and racial studies, vol. 28, $\mathrm{n}^{\circ}$. 6, noviembre: 1031-1086.

2006 "Edades, etapas de la vida y cohortes generacionales: un análisis de las dos primeras generaciones de inmigrantes en Estados Unidos", en Alejandro Portes y Josh DeWind (coords.), Repensando las Migraciones. Instituto Nacional de Migración, Universidad Autónoma de Zacatecas, México: 361-409.

Rumbaut, Rubén G. (Nancy Foner y Steven J. Gold)

1999 Transformations: Immigration and Immigration Research in the United States. Número especial de American Behavioral Scientist, $n^{\circ} 42,9$.

Rumbaut, Rubén G. (y Alejandro Portes)

2001 Ethnicities: Children of Immigrants in America. Berkeley and New York, University of California Press and Russell Sage Foundation.

Rumbaut, Rubén G. (y Walter A. Ewing)

2007 The Myth of Immigrant Criminality and the Paradox of Assimilation: Incarceration Rates among Native and Foreign-Born Men. Washington DC: Immigration Policy Center, American Immigration Law Foundation.

Salas Quintanal, Hernán

2011 "Identidades y globalización en el espacio fronterizo del noroeste de Sonora", en Cristina Oehmichen Bazán y Hernán Salas Quintanal (eds.), Migración, diversidad y fronteras culturales. UNAM, IIA: 125-144.

Schmid, Carol L.

2001 "Educational achievement, Language-Minority students and the new second generation", Sociology of Education, vol. 74: 71-87. 
Suárez-Orozco, Marcelo M. (y Carola E. Suárez-Orozco)

1995 "The cultural patterning of achievement motivation: A comparison of Mexican, Mexican immigrant, Mexican American, and Non Latino white American students", en Rubén G. Rumbaut y Wayne A. Cornelius (eds.), Californian's Immigrants Childrens. Center for U.S.-Mexican Studies, University of California, San Diego: 161-190.

Thomas, William I. (y Florian Znaniecki)

1918-20 The Polish Peasant in Europe and America, 5 vols. Boston, Badger.

Wimmer, Andreas (y Nina Glick-Shiller)

2003 "Methodological nacionalism and beyond: nation-state building, migration and the social sciences", Global Networks, n 2, 4: 301-334.

\section{Hemerografía}

Áviles, Karina

2010, "Unos 10 millones de jóvenes truncan sus estudios por carencias económicas" La Jornada (México), 4 de enero. 31.

Brooks, David

2010 "American curios", La Jornada, (México), 18 de junio.

Jalife-Rahme, Alfredo

2010 “Bajo la lupa“, La Jornada, (México), 8 de septiembre.

Nora Peterson

2012 "Young Immigrants Say It's Obama's Time to Act", The New York Times, 30 de noviembre.

De la redacción

2012. "Revela The Washington Post lista de PGR con 25 mil desaparecidos en el sexenio", La Jornada, (México) 1 de diciembre de 2012, p. 17.

\section{Referencias electrónicas}

http://www.city-data.com/city/California2.html [consulta 13 de mayo de 2011].

http://www.city-data.com/city/South-Lake-Tahoe-California.html [consulta 13 de mayo de 2011].

http://es.wikipedia.org/wiki/Modesto_(California)\#cite_note-MostMiserable-5 [consulta 13 mayo 2011].

http://www.city-data.com/city/California2.html [consulta 13 de mayo de 2011].

http://www.city-data.com/city/California2.html [consulta 13 de mayo de 2011].

http://www.indexmundi.com/g/g.aspx?c=us\&v=74 [consulta 15 de mayo de 2011].

http://translate.google.com.mx/translate?

hl=es\&langpair=en\%7Ces\&u=http://www.cde.ca.gov/fg/fr/eb/ [consulta 15 de mayo de 2011]. 